\title{
Residential Care Workers' Experiences with \\ Senior Trauma Survivors
}

Darcy J.E. Ammerman, B.A.

\author{
A thesis submitted to the \\ Faculty of Graduate Studies and Research \\ in partial fulfillment of the requirements for the degree of \\ Master of Arts \\ Department of Psychology \\ Carleton University \\ January, 2006
}




$\begin{array}{ll}\begin{array}{l}\text { Library and } \\ \text { Archives Canada }\end{array} & \begin{array}{l}\text { Bibliothèque et } \\ \text { Archives Canada }\end{array} \\ \begin{array}{l}\text { Published Heritage } \\ \text { Branch }\end{array} & \begin{array}{l}\text { Direction du } \\ \text { Patrimoine de l'édition }\end{array} \\ \begin{array}{l}\text { 395 Wellington Street } \\ \text { Ottawa ON K1A 0N4 }\end{array} & \begin{array}{l}\text { 395, rue Wellington } \\ \text { Ottana ON K1A ON4 } \\ \text { Canada Oa }\end{array}\end{array}$

Your file Votre référence ISBN: 0-494-13408-9

Our file Notre référence

ISBN: 0-494-13408-9

NOTICE:

The author has granted a nonexclusive license allowing Library and Archives Canada to reproduce, publish, archive, preserve, conserve, communicate to the public by telecommunication or on the Internet, loan, distribute and sell theses worldwide, for commercial or noncommercial purposes, in microform, paper, electronic and/or any other formats.

The author retains copyright ownership and moral rights in this thesis. Neither the thesis nor substantial extracts from it may be printed or otherwise reproduced without the author's permission.
AVIS:

L'auteur a accordé une licence non exclusive permettant à la Bibliothèque et Archives Canada de reproduire, publier, archiver, sauvegarder, conserver, transmettre au public par télécommunication ou par l'Internet, prêter, distribuer et vendre des thèses partout dans le monde, à des fins commerciales ou autres, sur support microforme, papier, électronique et/ou autres formats.

L'auteur conserve la propriété du droit d'auteur et des droits moraux qui protège cette thèse. $\mathrm{Ni}$ la thèse ni des extraits substantiels de celle-ci ne doivent être imprimés ou autrement reproduits sans son autorisation.
In compliance with the Canadian

Privacy Act some supporting forms may have been removed from this thesis.

While these forms may be included in the document page count, their removal does not represent any loss of content from the thesis.
Conformément à la loi canadienne sur la protection de la vie privée, quelques formulaires secondaires ont été enlevés de cette thèse.

Bien que ces formulaires aient inclus dans la pagination, il n'y aura aucun contenu manquant. 


\begin{abstract}
Sixty-two staff members ( $84 \%$ female) working in a range of positions at 6 different long-term care facilities completed a survey assessing their experiences working with seniors in general and senior trauma survivors in particular. The majority of participants $(77.4 \%)$ indicated that they had cared for at least one senior trauma survivor, and that many of them were exposed to verbal, physical or sexual abuse, and trauma-related triggers in the physical and social environment. Many also displayed PTSD symptoms. On average, care workers had little training regarding the effects of trauma, and only one facility routinely inquired into trauma during resident intake. In their responses to openended questions, participants offered procedural suggestions that may increase senior trauma survivors' well-being. They also commented on the personal burden of caring for traumatized seniors in residential care. The validity of these findings and their implications for future research and policy are discussed.
\end{abstract}




\section{Acknowledgements}

Thank you to Dr. Connie Kristiansen for your guidance and support. Thank you also to Dr. Tina Daniels, Dr. Michael Wohl, and Dr. Katharine Kelly for offering your valuable feedback and helping to shape this research into a worthwhile project. Thanks to those who provided feedback on the preliminary stages of this research including Sue Murray, Anne Lafortune, Riitta Vaissi Nagy, Janice Green, and Judith Alpert. Thank you also to Heather Phillips, Laurie Davison, Heather Hrushowy, and the rest of my surrogate family for offering your unwavering encouragement and perspective. "Short-term pain for longterm gain." And, of course, thanks to Mary Lou Snively and the rest of the family for always believing in me. 
The Effects of Trauma on Older Adults

Factors Affecting Senior Trauma Survivors' Psychological Well-Being .........................6

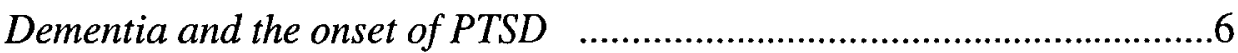

Aging and the psychosocial dynamics of trauma

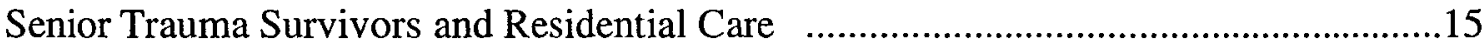

Dementia, PTSD, and residential care ...............................................15

Traumagenic dynamics and residential care ....................................17

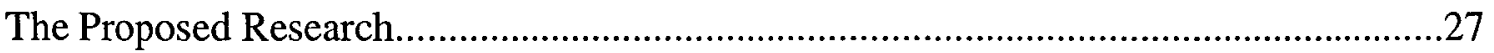

METHOD

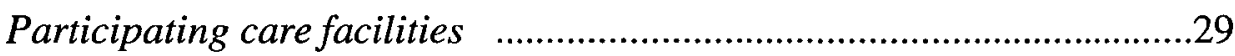

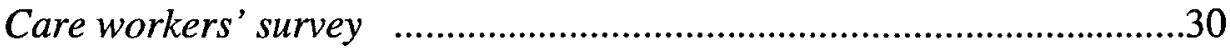

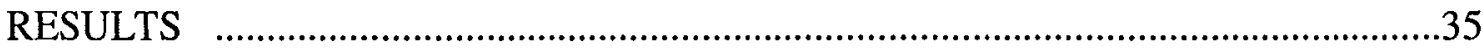

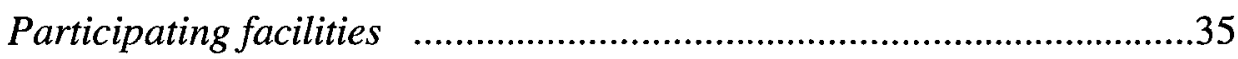

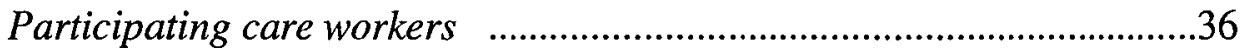

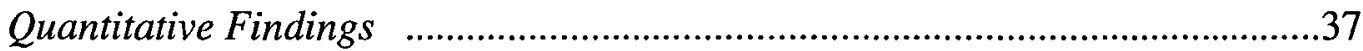

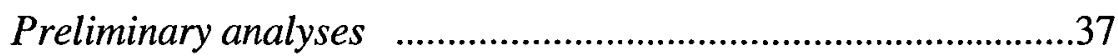

Experiences working with senior residents ..............................39

Experiences working with senior trauma survivors $\quad$..................42

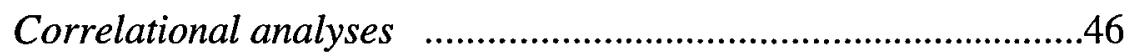

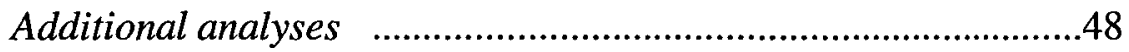

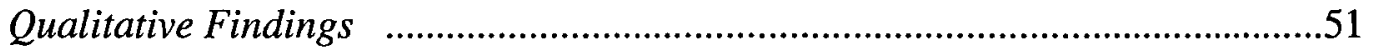

Suspecting trauma 
Triggers to thinking about trauma

Factors affecting trauma survivors' well-being ...........................53

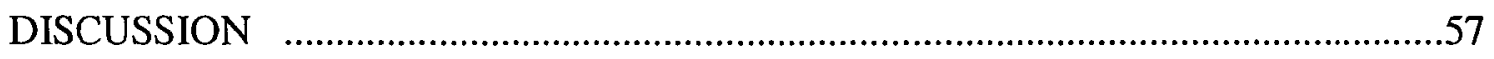

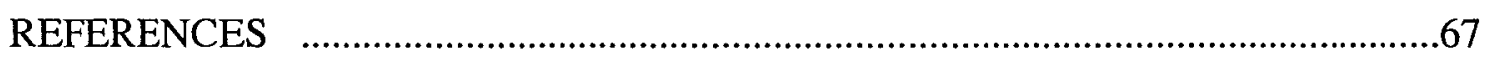

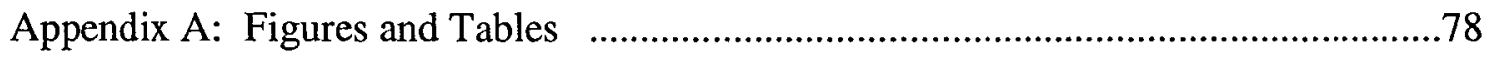

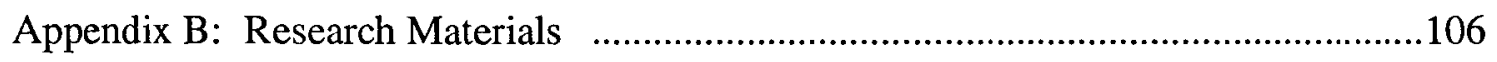




\section{List of Figures}

Figure 1: Baycrest Model of Caring for Aging Holocaust Survivors

Figure 2: Factors Affecting the Well-Being of Senior Trauma Survivors

in Residential Care .80 


\section{List of Tables}

Table 1: $\quad$ Characteristics of the Six Long-Term Care Facilities

Table 2: $\quad$ Trauma-Related Characteristics of the

Six Long-Term Care Facilities

Table 3: $\quad$ Results of Item Analyses and Descriptive Statistics for Scale Scores

Table 4: Descriptive Statistics for Measures of Participants'

Gerontology and Trauma-Related Training

Table 5: Descriptive Statistics for Measures of Participants'

Familiarity with Residents

Table 6: $\quad$ Frequency Participants Witnessed Potentially

Traumagenic Behaviours

Table 7: $\quad$ Number of Trauma Survivors Participants

Worked With by Type of Trauma .88

Table 8: $\quad$ Descriptive Statistics for Participants' Ratings of the Number

of Senior Trauma Survivors Having PTSD Symptoms

Table 9: $\quad$ Descriptive Statistics for Participants' Ratings of Other

Indicators of Senior Trauma Survivors' Well-Being

Table 10: $\quad$ Correlations of Participants' Training, Familiarity and Attitude

Scores with Frequency They Witnessed Traumagenic Dynamics

and Number of Trauma Survivors They Worked With

Table 11: Correlations of Participants' Training, Familiarity and Attitude

Scores with Measures of Senior Trauma Survivors' Well-Being

Table 12: $\quad$ Correlations Between Participants' Demographic Characteristics and the Conceptual Variables of the Study 
Table 13: $\quad$ Descriptive Statistics for Variables that Differed

as a Function of Contact

Table 14: $\quad$ Reasons for Suspecting a Senior Resident was Traumatized ..................96

Table 15: $\quad$ Other Effects of Trauma on Senior Residents

Table 16: $\quad$ Factors that Make Trauma Survivors Think of Their Trauma .............100

Table 17: $\quad$ Factors Facilitating Senior Trauma Survivors' Well-Being $\quad$................101

Table 18: $\quad$ Factors Detracting From Senior Trauma Survivors' Well-Being ........104

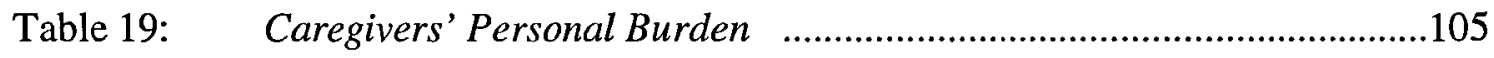

viii 


\section{Residential Care Workers' Experiences with Senior Trauma Survivors}

Increasing longevity, declining birthrates and the aging of the 'baby boomer' generation are having a profound effect on Canada's demographic structure. According to census data, the number of seniors aged 65 and older increased $10 \%$ between 1996 and 2001 (Statistics Canada, 2002a). Even more striking, the population aged 45 to 64 increased 36\% between 1991 and 2001 (Statistics Canada, 2002b). This growing number of seniors is posing a number of social, economic and political challenges, including those associated with the provision of responsible caregiving in senior residential care facilities (Kemper \& Murtaugh, 1991).

One area important to the well-being of seniors in residential care relates to the long-term effects of interpersonal trauma on seniors' lives, particularly how earlier traumatic experiences manifest themselves and affect seniors' needs. Seniors' experiences of interpersonal trauma are far from rare. Norris (1992), for example, interviewed 1000 adults in North and South Carolina about their experiences of ten potentially traumatic events. Of the 321 participants who were sixty years of age or older, $69 \%$ had experienced at least one of the traumatic events. The tragic death of a friend or relative was experienced most often (25.9\%), followed by robbery (24.1\%), combat $(20.4 \%)$, and a motor vehicle accident (19.8\%). In addition, $11.7 \%$ had experienced a fire, $8.6 \%$ had been physically assaulted and $1.9 \%$ had been sexually assaulted, while $12.3 \%$ had experienced some other disaster and $12 \%$ had experienced some other hazard.

Taken together, the increasing population of seniors and the likelihood that many have experienced some type of interpersonal trauma at some point in their lives form the 
impetus of this research. Specifically, this research is designed to examine whether nowsenior survivors of trauma living in residential care facilities encounter situations that may be reminiscent of their earlier trauma (e.g., situations that make them feel powerless), their unique needs, and how care providers might best meet these needs.

\section{The Effects of Trauma on Older Adults}

According to the American Psychiatric Association (APA, 2000, p. 463), a traumatic event is one that "involves actual or threatened death or serious injury, or other threat to one's personal integrity; or witnessing an event that involves death, injury, or a threat to the personal integrity of another person." Additionally, the person's response to the event must involve intense fear, helplessness, and horror, or disorganized and agitated behaviour in children.

One psychological response to trauma is posttraumatic stress disorder (PTSD), which is characterized by three sets of symptoms: intrusive memories, avoidance and hyperarousal (APA, 2000). Intrusive symptoms involve the persistent re-experiencing of the traumatic event in the form of recurrent and intrusive distressing recollections, frightening dreams, extreme psychological distress and/or physiological reactivity to situations resembling the event, and/or experiencing flashbacks or other dissociative states, which may be coupled with acting out the traumatic event. Avoidance symptoms involve the active avoidance of stimuli associated with the event, such as emotions, thoughts, places and people, or a general detachment and numbing of responsiveness to participation in activities, loved ones, or planning for the future. Finally, persistent increased arousal manifests itself in the form of hypervigilence, an exaggerated startle response, angry outbursts, and difficulty concentrating or sleeping. 
While PTSD is often sufficient to capture the aftereffects of acute nonhuman traumas such as car accidents or natural disasters, more chronic interpersonal traumas such as child abuse, partner abuse, and being imprisoned during a war are often associated with additional symptoms (APA, 1994). These symptoms include impaired affect modulation (e.g., impulsiveness and risk-taking, self-destructive and suicidal behavior, difficulty regulating anger), alterations in attention and consciousness (e.g., amnesia, dissociation), somatization, chronic changes in character that include changes in self-perceptions (e.g., chronic guilt and shame, self-blame, feeling ineffective and damaged) and changes in relations with others (e.g., inability to trust or maintain relationships, being revictimized or victimizing others), and alterations in systems of meaning (e.g., loss of previously sustaining beliefs, depression). Taken together, these symptoms are often referred to as Complex PTSD or Disorders of Extreme Stress Not Otherwise Specified (e.g., Herman, 1992; Roth et al., 1997; van der Kolk, 1996; van der Kolk et al., 1996).

Both PTSD and Complex PTSD have been observed in senior trauma survivors. In Norris' (1992) study of people's exposure to a range of traumas, for example, $4 \%$ of the seniors exposed to trauma had PTSD. Specifically, $3.3 \%$ of the seniors who had experienced a crime (i.e., robbery, physical or sexual assault), $4.1 \%$ of those exposed to a hazard (i.e., fire, natural disaster), 3.9\% of those exposed to an accident (tragic death, motor vehicle crash), and $2 \%$ of the combat veterans satisfied the diagnostic criteria for current PTSD.

Even higher rates of PTSD have been observed in studies of seniors' exposed to particular types of interpersonal traumas, such as studies of senior war veterans, prisoners 
of war (POWs), concentration camp survivors and victims of violence toward women and children. In particular, PTSD rates range from $14 \%$ to $67 \%$ among older war veterans (e.g., Jongedijk, Carlier, Schreuder, \& Gersons, 1996; Sutker \& Allain, 1996; Weintraub \& Ruskin, 1999), from 29\% to 96\% among former POWs (e.g., Engdahl, Dikel, Eberly, \& Blank, 1997; Sutker \& Allain, 1996; Weintraub \& Ruskin, 1999), and from 22\% to $65 \%$ in now-senior Holocaust survivors (e.g., Joffe, Brodaty, Luscombe, \& Ehrlich, 2003; Kutch \& Cox, 1992; Yehuda, Kahana, Southwick, \& Giller, 1994). ${ }^{1}$

Other researchers have documented the symptoms associated with PTSD in senior survivors of violence toward women and children. In a study by Gentlewarrior (1997), for example, 125 professional women who had experienced childhood sexual abuse responded to two postal surveys assessing their experiences of trauma and their wellbeing. Of these women, $39 \%$ reported adult experiences of rape and/or partner abuse and/or witnessing another person being assaulted, injured or killed. Comparing the 67 middle-aged (29 - 59 years) and 58 senior women (60 - 90 years) revealed no differences in their experiences of other traumas or PTSD-related symptoms (e.g., anxiety, dissociation, depression, intrusive memories or images of trauma). Given these findings, Gentlewarrior (1997, p. 108) concluded, "even with extensive sociocultural privilege in adult life, the traumatic effects of child sexual abuse can linger across the lifespan."

Similar findings were observed in Higgins (1999) study of 102 San Franciscobased women over the age of 60 , of whom $72 \%$ reported experiencing at least one form of interpersonal trauma at some point in their lives. Specifically, $28 \%$ reported child

\footnotetext{
${ }^{1}$ The variation in the rates of PTSD across studies is likely due to differences in the severity of the trauma, with more severe trauma contributing to more severe psychological aftereffects (Hocking, 1970), as well as the nature of the sample (e.g., clinical vs. nonclinical) and the way in which trauma and PTSD were measured.
} 
physical abuse, $30 \%$ child sexual abuse, $18 \%$ adolescent sexual abuse, $24 \%$ adult rape and $49 \%$ partner abuse. In addition, $69 \%$ reported experiencing a natural disaster, $48 \%$ had experienced a life threatening illness, $39 \%$ had been involved in a serious accident, $28 \%$ had witnessed a violent death, $22 \%$ had close friend or family member who was killed and $7 \%$ had been physically assaulted by a stranger. Relevant here is the finding that women who experienced at least two types of interpersonal trauma more frequently experienced a range of PTSD-related symptoms (e.g., anxiety, intrusive thoughts, avoidance), were more depressed and globally distressed, had more health problems, and took more medications compared to those who experienced one or no interpersonal traumas.

A growing number of case studies also point to the long-lasting negative effects of child abuse on seniors (e.g., Allers, Benjack, \& Allers, 1992; Gagnon \& Hersen, 2000). McInnis-Dittrich (1996), for example, presented four case studies of senior survivors of childhood sexual abuse. One involved a 68-year single woman whose presenting symptoms included those associated with Complex PTSD, namely selfmutilation, suicidal ideation, frequent accidents, severe depression, isolation, and difficulty concentrating.

Not only are senior trauma survivors vulnerable to PTSD, the nature of PTSD may vary across the lifespan, manifesting in the form of exacerbated, re-emergent or delayed-onset PTSD. Evidence of the exacerbation of ongoing PTSD is provided by Kaup, Ruskin, and Nyman (1994), whose analyses of clinical records indicated that 14\% of 20 World War II veterans showed an exacerbation of their PTSD symptoms that coincided with the onset of late life stressors, such as retirement and the loss of family 
and friends. In addition, those whose symptoms were exacerbated had more late life stressors.

Both re-emergent and delayed-onset PTSD were observed in Port's (1998) fouryear longitudinal study of 179 now-senior POWs. These POWs' PTSD scale scores increased over time, with $27 \%$ of the participants meeting the diagnostic criteria for PTSD at Time One compared to $34 \%$ four years later. Of those who were enlisted in WWII, $11 \%$ experienced reactivated PTSD that returned after 30 symptom-free years and an additional 2\% experienced delayed-onset PTSD in that they had no difficulties with PTSD until 55 years after the war. Thus, $13 \%$ of these WWII POWs experienced either re-emergent or delayed-onset PTSD. Other studies, including case studies, describe the re-emergence of PTSD with age (Aarts \& Op den Velde, 1993), as well as PTSD that first developed 20 (Op den Velde et al., 1993) or 30 years after combat (Falk, Hersen, \& Hasselt, 1994; Pary, Turns, \& Tobia, 1986). Case studies also illustrate re-emergent and delayed-onset PTSD on the part of aging survivors of the Holocaust and violence against women and children (Aarts \& Op den Velde, 1996; Allers, Benjack, \& Allers, 1992; Gagnon \& Hersen, 2000; McInnis-Dittrich, 1996).

Factors Affecting Senior Trauma Survivors' Psychological Well-Being

At least two factors have the potential to detract from senior trauma survivors' well-being and contribute to exacerbated, reactivated and delayed-onset PTSD. These factors involve dementia and exposure to the psychosocial dynamics associated with trauma.

Dementia and the onset of PTSD. One of the many chronic health problems associated with aging is dementia. The most common form of dementia among the older 
population is Alzheimer's type dementia (AD). AD rates jump with increasing age, rising from $0.6 \%$ of males and $0.8 \%$ of females at age 65 to $36 \%$ of males and $41 \%$ of females at age 95 (APA, 2000). Other types of dementia include dementia due to HIV disease, head trauma, Parkinson's Disease, Huntington's Disease, Pick's Disease, Creukzfeldt Disease, and dementia due to other general medical conditions (APA, 2000), and all forms of dementia are associated with a number of cognitive deficits, including memory impairment, agnosia (failure to recognize or identify objects despite intact sensory function), apraxia (inability to carry out motor functions despite intact motor function), aphasia (language impairment), aphasia (language disturbance) and a general disturbance in planning and organizing.

Recently, a number of case studies have documented a relationship between the onset of dementia and the emergence of PTSD. For example, Johnston (2000) described three aging World War II veterans for whom the onset of dementia was associated with PTSD. Although the early signs of dementia (e.g., deterioration of memory, disorientation) were witnessed by spouses and family members, in each case a violent episode associated with reliving war-related trauma occurred before PTSD was diagnosed. One case involved a 77-year old WWII combat veteran who was found unfit to stand trial after shooting his wife five times from a fort he constructed in their living room. Although he had been having violent nightmares and talking about his wartime experiences, this was the first violent act he had ever committed in civilian life. Unfortunately, prior to this event his caregivers misattributed his symptoms of delayedonset PTSD to his dementia. 
van Achterberg, Rohrbaugh, and Southwick (2001) also described the onset of PTSD following dementia in their case studies of a combat veteran, a Holocaust survivor and a Titanic survivor. Again, these seniors experienced few PTSD symptoms prior to of the onset of dementia, at which point they began to exhibit intrusive thoughts of their former trauma, increased irritability and agitation, and flashbacks. One case involved Ms. A, who survived the Titanic when she was 22 years of age. Ms. A was placed in a nursing home at the age of 95 when she began showing signs of dementia (e.g., memory loss, apraxia, and agnosia). Her family also said that, apart from avoiding any discussion of the Titanic, Ms. A did not appear to experience any PTSD symptoms until she was placed in long-term care, where she began to experience episodes of extreme agitation and relive her earlier trauma. Calling out to other patients in the common area, "The water is coming up! Go to the lifeboats! Save the children! We'll all be dead!" Ms. A was clearly reliving her trauma.

Another case described by van Achterberg et al. involved Ms. C, an 83-year old widowed survivor of the Holocaust. Somewhat isolated during her life as a mother and homemaker, Ms. C suffered mild symptoms of PTSD, such as intrusive memories triggered by environmental cues, nightmares, increased startle response and suspiciousness. After five years of memory loss, apraxia and difficulties in executive functioning, Ms. C was diagnosed with dementia. Shortly after admission to a nursing home, Ms. C. began re-experiencing her traumatic time in a resettlement camp and began speaking German. She exhibited extreme fear and agitation, and was particularly suspicious and combative with the nursing staff, whom she believed were Nazis. As a result, caring for Ms. C. was difficult for the nursing staff. 
Interestingly, the traumatic relivings of both Ms. C and Ms. A began shortly after their admission to care. Ms. A's re-experiencing seemed to be triggered by the social group environment, which may have been similar to the group environment on the Titanic. Similarly, Ms. C's combative behaviour toward the nurses appeared to be connected to their authoritative role, which may have been reminiscent of that of the Nazis. Thus, "environmental cues often serve as triggers for the re-experiencing of past traumas" (van Achterberg et al., 2001, p. 206).

Most recently, Grossman, Levin, Katzen, and Lechner (2004) described two senior Holocaust survivors who "appeared to have adapted well post-trauma, but developed severe PTSD symptomatology following the onset of' (p. 698) dementia. After ruling out alternative explanations, including the possibility that their PTSD developed in response to their dementia, Grossman et al. concluded that "cognitive decline added a layer of complexity, in that it diminished the capacity to inhibit the intrusive traumatic memories of their pasts" (p. 702), resulting in a tendency to perseverate on these memories and the re-emergence of PTSD and depression. The contribution of dementia to PTSD seems particularly likely given that none of the seniors described by van Achterberg et al. (2001) had experienced the loss of friends and family or any other late life stresses that might have contributed to the onset of PTSD. It is also consistent with the comparable neurobiology of both disorders, including the decline of the brain structures associated with explicit, conscious memory and the intactness of the brain structures associated with implicit or nonconscious memory (Mittal, Torres, Abashidze, \& Jimerson, 2001). Thus, the neurobiological changes associated with dementia appear to pave the way for PTSD on the part of aging trauma survivors. 
Aging and the psychosocial dynamics of trauma. Senior trauma survivors may also suffer exacerbated, re-emergent or delayed-onset PTSD because aging and the stressors associated with aging replicate the psychosocial dynamics they experienced during their traumatization (Kristiansen, 2003; Kristiansen \& Hay, 2000; Shmotkin et al., 2003). These psychosocial dynamics instill particular feelings, most notably powerlessness or lack of control, stigmatization or shame, and a sense of betrayal (Finkelhor \& Browne, 1985; Kristiansen, 2003; Kristiansen \& Hay, 2000). Perhaps the most fundamental of these dynamics is powerlessness (Kristiansen, 2003). Indeed, the APA (2000, p. 463) defines a traumatic event as one where "the person's response to the event must involve intense ... helplessness." A victim of child abuse, for example, is rendered powerless by an adult abuser's age, status and physical prowess. Adult survivors of rape and battering may also be powerless given male perpetrators' physical strength as well as their use of threats (Heney \& Kristiansen, 2003). Similarly, soldiers drafted involuntarily may feel powerless to stay with their families or leave the military (Granatstein, 1969) and, once in combat, powerless in the face of the enemy. The lack of freedom and maltreatment encountered by prisoners of war and those in concentration camps makes their powerlessness strikingly clear. Senior trauma survivors may encounter similar feelings of powerlessness as a result of their increasing frailty, declines in mental agility and increasing dependence on benevolent caregivers, and these feelings of powerlessness may contribute to symptoms associated with PTSD.

Interpersonal trauma is also associated with stigmatization (Kristiansen, 2003; Kristiansen \& Heney, 2003). During childhood sexual abuse, feelings of stigma and shame are instilled by the abuser's negative messages (e.g., that hold the child 
responsible for the abuse) and the social secrecy shrouding sexual abuse (Finkelhor \& Browne, 1985; Summit, 1983). Similar secrecy and shame are also associated with adult women's experiences of rape and partner abuse, and combat veterans may be stigmatized for participating in unpopular wars (Aarts \& Op den Velde, 1993) such as the Korean conflict or the Vietnam War. Moreover, war veterans, POWs and concentration camp survivors may be shamed by the things they did to survive.

Senior trauma survivors may experience comparable stigmatization and shame as a result of society's ageism (Friedan, 1993; Pearlman, 1993). Palmore (2001), for example, found that over $77 \%$ of 84 respondents aged 60 to 93 reported experiencing at least one incident of ageism, such as being called insulting names or being patronized. Moreover, Hausdorff, Levy, and Wei (1999) found that ageism affects seniors' behaviour. In their study, 47 healthy women and men aged 63 to 82 years were randomly and blindly assigned to view words associated with either a positive or a negative stereotype of aging that were displayed subliminally on a computer screen. Those who viewed words associated with a positive stereotype of aging subsequently walked faster and displayed greater gait speed (time spent with one foot in the air during walking) than at baseline. No change in walking was evident on the part of participants who had been primed with words associated with a negative stereotype of aging, conceivably because exposure to negative stereotypes of aging was the norm. Given these findings, it is not unreasonable to suggest that ageism may induce the feelings of shame that senior trauma survivors experienced during their original traumatization.

The third psychosocial dynamic associated with interpersonal trauma is betrayal. A child feels betrayed when a trusted person harms them, when others fail to protect 
them, and when their disclosures of abuse are disbelieved (Summit, 1983). An adult woman may feel betrayed when she is assaulted by her partner and when the police or courts leave her feeling revictimizied (Kristiansen, 2003). War veterans may feel betrayed when society rejects them or their family members fail to understand their combat-related PTSD. POWs may feel betrayed when no one comes to their rescue. Similarly, Holocaust survivors may have felt betrayed by friends who refused to help them, by family members who were unable to save them, and by a society that allowed the Holocaust to happen. Seniors trauma survivors' feelings of betrayal may be rekindled by the ageism they encounter, the decline of their physical bodies or minds, and by people who fail to live up to their expectations (e.g., family members who put them in residential care).

That senior trauma survivors may be exposed to psychosocial dynamics similar to those associated with their original traumatization is important because trauma survivors' well-being varies as a function of the extent to which they experience these dynamics in their current lives. Perhaps the strongest evidence of the impact of current experiences of the psychosocial dynamics associated with trauma on the well-being of senior trauma survivors comes from a study by Wickett and Kristiansen (2005). In this study, over 300 community-based seniors at least 60 years of age completed a survey assessing their experiences of interpersonal trauma, the frequency of their exposure to situations that might make them feel powerless, stigmatized or devalued, and betrayed, and their psychological well-being. Path analyses revealed that seniors who experienced more interpersonal traumas (e.g., war-related, violence against women and children) during their lives reported more frequently being exposed to the psychosocial dynamics 
associated with trauma during the past six months, which in turn contributed to higher scores on a measure of PTSD-related symptoms (e.g., anxiety, intrusive thoughts). In addition, seniors who experienced more interpersonal traumas reported more current stressors in their lives (e.g., illnesses or deaths of loved ones, relational problems), and the frequency of seniors' exposure to the psychosocial dynamics associated with trauma mediated the impact of these stressors on their psychological well-being.

Other studies also indicate that exposure to dynamics similar to those encountered during a traumatic event has adverse effects on trauma survivors' well-being. For example, in a test of Finkelhor and Browne's (1985) traumagenic model of childhood sexual abuse, Coffey, Leitenberg, Henning, Turner, and Bennett (1996) had 192 community-dwelling women ( $M$ age $=40$ years) who had been sexually abused during childhood complete measures of the extent to which they currently experienced feelings of powerlessness, stigma, betrayal, and self-blame in their lives. Regression analyses revealed that these women's current feelings of stigma and self-blame predicted their scores on the Global Severity Index of the Brief Symptom Inventory (BSI). Additional support for Finkelhor and Browne's (1985) model was found in Hazzard's (1993) study of 56 female survivors of childhood sexual abuse ( $M$ age $=39$ years) where women's current feelings of powerlessness, self-blame/stigmatization, and betrayal and were associated with interpersonal problems, depression, psychological distress, anxiety and low self-esteem. Further, Leskela, Dierperink, and Thuras (2002) reported that, in a sample of 107 now-senior community-residing POWs, those with higher shameproneness scores had moderately higher PTSD scores. Moreover, the relation between 
shame-proneness and PTSD remained significant even after controlling for the extent of POWs' combat exposure and percent weight loss during captivity.

That current experiences of the dynamics associated with trauma affect senior trauma survivors' well-being is also indicated by the findings of Baider, Peretz, and Kaplan De-Nour (1992, 1993). In one study (Baider, Peretz, \& Kaplan-Denour, 1992), 53 senior cancer patients who had survived the Holocaust were matched with 53 cancer patients who had not experienced any severe life threat for age, gender, medical treatment, education, marital status, stage of cancer, and time since cancer diagnosis. Relative to the control group, the Holocaust survivors scored higher on measures of both their avoidance of their cancer (e.g., efforts to avoid thinking or talking about their cancer) and the intrusiveness of their cancer (i.e., intrusiveness of the cancer into their lives), and all of the subscales of the BSI.

In a subsequent study, Baider, Peretz, and Kaplan De-Nour (1993) compared the BSI scores of these Holocaust survivors with cancer with those of a matched group of 50 healthy Holocaust survivors. Analyses of these data indicated that the Holocaust survivors with cancer had higher scores on all of the BSI scales, with the exception of depression. Taken together, these findings suggest that Holocaust survivors over-react to current stressors, such as cancer, with the pattern of increased intrusiveness and avoidance associated with PTSD. Because both cancer and the Holocaust "are associated with fears of pain, disfigurement and disability .... uncertainty, loss of personal control .... social rejection [and] a sense of total helplessness," (Baider et al., 1992, p. 12), the authors concluded that, "people who have undergone varying but severe traumas in the past may recover but remain at constant risk and are likely to develop extreme 
psychological distress when faced with a new threat that has similar components or associative elements to the past traumas" (Baider et al., 1993, p. 354).

The feelings seniors experienced during their earlier trauma may also be rekindled by experiences of additional trauma, such as elder abuse. In a Canadian survey of 2008 randomly selected community dwelling seniors by Podnieks and her colleagues (1990), $4 \%$ reported experiencing one type of elder abuse and $0.8 \%$ reported experiencing more than one type. Material abuse (e.g., someone trying to persuade the respondent to give money) was experienced most frequently (2.5\%), followed by verbal abuse (1.4\%), physical abuse (0.5\%) and neglect (0.4\%). Taken together, Podnieks et al. (1990) estimated that 98,000 Canadian seniors have been victims of at least one form of elder abuse. Similar rates of elder abuse have been reported in other studies (e.g., Comijs et al., 1998; Pillemer \& Finkelhor, 1988).

\section{Senior Trauma Survivors and Residential Care}

That dementia and exposure to the psychosocial dynamics associated with trauma may adversely affect senior trauma survivors and contribute to the exacerbated, reemergent and delayed-onset PTSD observed in senior trauma survivors has important implications for senior trauma survivors in residential care.

Dementia, PTSD and residential care. A good number of seniors in residential care suffer from some form of dementia. Nevertheless, virtually none of the literature regarding caring for seniors with dementia considers the impact of trauma. For example, in her guide for caregivers of seniors with Alzheimer's dementia, Parrent (2001) includes a discussion on "rage and catastrophic outbursts" in which she advises caregivers to look for the reason for the angry outburst (e.g., noisy environment, changes in routine or 
structure, discomfort during the night) and any possible patterns. Distraction and ignoring the behaviour are suggested as ways of stopping the outburst. Unfortunately, Parrent (2001) fails to address the possibility that a history of trauma underlies the behaviour.

A similar omission is apparent in Rockwood and MacKnight's (2001) manual for caregivers of seniors with dementia. They suggest a nonpharmacological treatment for dementia patients that entails caregivers treating underlying medical precipitants, noting the patterns of problem behaviours, and assessing potential precipitating factors in the environment. The authors state that, unfortunately, "Where no precipitant can be found, then pharmacologic management is commonly the next resort" (2001, p. 166). Thus, caregivers' lack of knowledge of seniors' histories of trauma and the long-term effects of trauma suggest that senior trauma survivors with dementia may face chemical restraint.

Stones (1997), however, briefly mentions the implications of earlier trauma, stating that, "people who have been in concentration camps, prisons, or have been tortured, are likely to feel that they are back in those horrendous and fearful circumstances if they become agitated in an institutional setting" (p. 46). He described a former sailor who was triggered by a puddle on the floor caused by a blocked toilet. He screamed, "I'll drown! I'll drown," mistaking the puddle for the floor of a boat. The caregiver responded to the senior by passing him a towel and telling him to grab hold of the lifebelt, assuring he would be safe. This response, along with removing the senior from the bathroom, appeared to calm this senior trauma survivor with dementia.

To the extent that workers in senior residential facilities are unaware of the comorbidity of dementia and PTSD, senior trauma survivors' symptoms of PTSD may be 
misattributed to their dementia and, as a result, go untreated. This seems particularly likely given the findings of a study by Cooper and Kristiansen (2004). In this study, 230 clinicians responded to a case history describing a 71-year old male (vs. female) survivor of childhood sexual abuse (vs. the Holocaust) whose symptoms, although ambiguous, fulfilled the diagnostic criteria for both PTSD and dementia. That these psychiatrists and clinical psychologists gave the senior trauma survivor higher diagnostic ratings for dementia than PTSD, despite their clinical training, suggests that the staff of residential care facilities may be especially likely to make such ageist misattributions.

Traumagenic dynamics and residential care. Fromuth and Burkhart (1992) and Heney and Kristiansen (1997) described how psychiatric and correctional facilities may revictimize adult survivors of child abuse precisely because they reinstate the psychosocial dynamics of trauma. Conceivably, the same may be true of seniors' residential facilities. Because the staff of residential facilities have the potential to control virtually every aspect of seniors' lives (e.g., when, where and what they eat, when they sleep, and what they wear), the staff-resident power differential may replicate the abuser-victim power differential experienced during child or partner abuse and the captor-hostage power differential experienced in POW and concentration camps. Senior trauma survivors may feel particularly powerless in situations that involve intimate personal care (i.e., bathing, washing, and dressing), during which they may have little say over who touches their body and in what way. Interestingly, powerlessness has been noted as contributing to aggressive or difficult behaviours on the part of seniors in care (David \& Pelly, 2003; Rockwood \& MacKnight, 2001). 
That seniors in residential care are rendered powerless has been well documented. In their analysis of conversations between physicians and elderly patients, Wood and Kroger (1993) found that certain forms of address put elderly people in positions of powerlessness. These include addressing an elderly patient by their first name, which may indicate that the status of the elderly person has declined, or saying their first name loudly and often, which may indicate the belief that the older person has certain cognitive impairments that make the repetitive use of their first name warranted even though they do not have any disability. Other forms of address also render seniors powerless, including those that infantilize seniors (e.g., 'sweetheart' or 'girl').

This 'disempowerment' of seniors is consistent with the findings of Nussbaum's (1993) observational study of communication in a nursing home. In his observations of the admission of an 82 year-old woman, he noted that the senior woman was not an active participant in the admission process in that very little talk was directed toward her and, when it was, it involved explaining non-negotiable procedures. Nussbaum argued that this type of communication (or lack of) reinforced the resident's dependence (or imminent loss of independence). Grainger (1993) observed similar discursive practices during nurses' interactions with 30 elderly patients in two long-term care facilities. Based on their interactions, she found that the patients were objectified and that the requirements of the institutions were prioritized over the needs of the patients (e.g., responding to an elderly man's comment that he was not feeling well by instructing him to get up and begin the daily routine, rather than responding on a personal level to his problem). Specifically, she identified four modes of discourse. Routine management discourse (e.g., "take your dress off," "stand up a minute") was part of the nurses' task- 
orientated goals but put the nurse in a controlling position and, by implication, defined the patient as passive. Nurturing discourse, which was comprised of a loving, intimate style of discourse (e.g., "alright my darling"), cast the nurse in a nurturing role and the patient in a needy, dependent role. Sick/dependent discourse, which involved patients' complaints and expressions of pain and discomfort (e.g., "it's too painful"), reinforced the resident's dependence when the nurse expressed sympathy. Finally, personal discourse involving sociable, non-institutional talk between nurses and patients (e.g., “where's your home?”) was rarely engaged in, or responded to, by nurses. Grainger suggests that these types of exchanges contribute to senior residents' loss of control over themselves and their environment, as well as the loss of their identity and self-esteem.

The negative effects of powerlessness on seniors were vividly documented in a study by Langer and Rodin (1976), who selected two floors of a nursing home with demographically similar residents and randomly assigned the 47 residents on one floor to the treatment group and the 44 residents on the other floor to the control group. Unlike the residents in the control group, those in the treatment group were allowed to arrange the furniture in their rooms, care for a houseplant, and select their own recreational activities. Strikingly, after only three weeks $93 \%$ of residents in the treatment group were happier, more active and alert, and reported higher levels of general well-being compared to those in the control group. In fact, most (71\%) of the residents who had no control over their environment became more physically debilitated, less active, and less alert. Further, 18 months after the onset of the study the residents in the treatment group remained happier, more active and sociable, and had half the mortality rate of the residents who were unable to control these day-to-day activities (15\% vs. $30 \%$, 
respectively) (Langer, 1983). Consistent with these profound effects of powerlessness on seniors' well-being, Lee and Carr (1993) described how the major issue articulated by the senior women living in five nursing homes was their need for more control and input into their daily lives, including having more input into the selection of a roommate, the ability to assist with food planning and preparation, and the availability and choice of meaningful social activities. As a result, these authors recommended "the creation of as many opportunities as possible for residents to increase their autonomy and take control of their lives" (Lee \& Carr, 1993, p. 200).

In addition to being rendered powerless, data suggesting that many care workers have negative attitudes toward seniors suggests that seniors in residential care facilities may also be stigmatized and shamed. Campbell (1971), for example, found that a sample of 50 registered nurses agreed with half of 88 negative age-related statements (e.g., "They are untidy and careless about their appearance." "They never take a bath." "They are not useful to themselves or to others."), while 48 licensed practical nurses and 49 nursing assistants agreed with more than $60 \%$ of the statements. While the nursing staff with more training appeared to have more positive attitudes toward seniors, the licensed practical nurses and the nursing assistants preferred working with old people more than the registered nurses did. In addition, registered and licensed practical nurses who had graduated within the last 10 years viewed seniors more negatively than those who had graduated more than 10 years ago. More recently, however, Hefner (2001) found that nursing personnel with more education and training had more negative attitudes toward the seniors they cared for. 
Haight, Christ, and Dias (1994) found that nurse trainees $(n=86)$ developed more positive attitudes toward seniors after completing a course on caring for healthy elderly people. Importantly, however, the authors also found that nurse trainees' attitudes became more negative after completing a course on caring for the ill elderly, and even more negative after completing a course on caring for the critically ill elderly. Thus, nurse trainees' attitudes appear to be contingent on the well-being of the seniors they tend to.

Finally, a meta-analysis by Kite, Stockdale, Whiley, and Johnson (2005) concluded that the older participants in the 232 studies that were examined (i.e., those aged 55 and older) had the most favourable attitudes toward seniors, while the middleaged people (those aged 36-54 years) had the most negative attitudes toward seniors, followed by younger people (those aged 21-35 years). They also found that providing more individuating, detailed information about the senior being assessed resulted in more positive attitudes toward them.

In general, then, studies of the potential moderators of nursing personnel's attitudes towards seniors are inconclusive. However, variables such as the health of the seniors being cared for, the length of time since nursing training and/or age, and amount of information available about the seniors being assessed appear to be important.

Finding ways of increasing the favourability of nurses' attitudes toward the seniors they care for is imperative, as those who view seniors more negatively report little satisfaction or reward when working with them. This may result in "nurses who are not providing the potentially highly skilled nursing care that is needed so desperately in these settings" (Brower, 1981 p. 298). Moreover, as described by Ingham and Fielding (1985), 
nurses who believe that seniors are helpless and incapable of learning are likely to elicit these behaviors through their communication with senior residents. The authors also claim that the corresponding behaviour from residents may then contribute to the original negative stereotype in a self-fulfilling fashion, thereby increasing the likelihood of care workers contributing to a climate that reinstates the stigma and shame associated with trauma.

Seniors in residential care may also feel stigmatized and shamed by 'elderspeak.' Elderspeak, which is marked by speaking more slowly or loudly, exaggerated intonation, higher pitch, simplified grammar, and/or terms of address such as "dearie," is based on ageist stereotypes that depicting seniors as incompetent, dependent, and having poor communication skills (Grainger, 1993). Several studies indicate that many senior recipients view elderspeak as condescending, disrespectful, and infantilizing ( $\mathrm{O}^{\prime} \mathrm{Connor}$ \& St. Pierre, 2004; Ryan, Bourhis, \& Knops, 1991; Ryan, Meredith, MacLean \& Orange, 1995). In one such study O'Connor and St. Pierre (2004) assessed the perceptions of seniors living in the community $(n=131)$ and in nursing homes $(n=28)$ about their experiences of elderspeak from friends, same-age family members, younger family members, familiar service workers, and unfamiliar service workers. They found that seniors living in nursing homes received at least twice as much elderspeak as those living in the community (i.e., 6 to 10 times per week vs. 1 to 5 times per week, respectively) and that elderspeak was more common on the part of unfamiliar service workers (e.g., unfamiliar doctors, nurses, physical therapists, etc.) than familiar staff, friends, and family members. In addition, elderspeak was more frequently directed at older relative to younger seniors, and was perceived as colder and more superior when perpetrated by 
unfamiliar service workers than by friends and same-age family members. Consistent with the contact hypothesis (Allport, 1954, as cited by Meshal \& McGlynn, 2004), then, staff who were unfamiliar to the respondents were perceived as more ageist and as using more elderspeak to communicate with the senior respondents than service workers who were familiar to the senior. Thus, to the extent that seniors living in residential facilities are cared for by different staff each day, it is likely that they are exposed to demeaning elderspeak and the negative attitudes and stereotypes associated with it.

Finally, just as an adult abuse survivor may feel betrayed if she is hospitalized against her will (Fromuth \& Burkhart, 1992) or incarcerated for using drugs to soothe her psychic pain (Heney \& Kristiansen, 1997), a senior trauma survivor may feel betrayed if their family institutionalizes them without their consent (Danieli, 1997) or fails to live up to expectations (e.g., regarding visiting). A senior in residential care is also likely to encounter various betrayals within the institution, including staff who fail to live up to promises and people who betray their trust.

Feelings of powerlessness, stigmatization and betrayal may also be reinstated by the experience of a further traumatic event, such as elder abuse. Unfortunately, elder abuse occurs in senior residential care facilities at an alarming rate. In Pillemer and Moore's (1989) telephone survey of 577 nurses and nursing aides, $36 \%$ said that, during the past year, they had witnessed at least one instance of a staff member physically abusing a resident and $81 \%$ said they had witnessed at least one instance of psychological abuse. In addition, $10 \%$ admitted that in the past year they themselves had physically abused a resident and $40 \%$ admitted perpetrating psychological abuse. Workers who 
viewed residents as child-like, those with higher burnout scores, and those who more frequently thought of quitting were more likely to commit such abuse.

Seniors in residential care may also be abused by other residents. ShinodaTagawa et al. (2004) examined the records of 294 senior residents who had sustained a visible injury as a result of abuse by another resident (13\% had sustained fractures, $2 \%$ dislocations, $36 \%$ lacerations and $38 \%$ had reddened areas). Comparing these abused residents with 1994 randomly selected residents with no records of injury, the authors found that the abused residents had more cognitive impairments, were more independent in their activities of daily living, and were more likely to wander, be verbally or physically abusive, engage in disruptive behavior and resist care. Further, residents in an Alzheimer's unit were more likely to be injured than those living in other units ( 25 vs. $2 \%$ were injured, respectively). Thus, senior trauma survivors with dementia who act aggressively within the context of reliving their trauma may be vulnerable to additional traumatization while in residential care.

Seniors in residential care are also vulnerable to sexual abuse. Benbow and Haddad (1993) described four seniors who were sexually abused while in residential care, including an 84-year old woman whose caregiver "washed her privates, making her sore and distressing her" (p. 804) and a 62-year old male resident with pre-senile dementia who was caught attempting to rape a severely demented woman. Burgess, Dowdell, and Prentky (2000) studied 20 civil law suits involving sexual abuse against a nursing home resident. Most of the 20 residents were women over the age of 70 who suffered from dementia. In all cases, someone other than the victim reported the rape to the nursing home administration, who then decided whether to report the incident to law 
enforcement. Symptoms of trauma were noted in all victims, such as fear and avoidance of male staff, being withdrawn, lying in bed in a fetal position, being anxious or agitated during personal care, the refusal of care, appetite changes, sleep disturbances, and reenactment behaviours. In one case, a female resident with dementia talked of disobeying her parents. According to the authors, "it was if she had been raped as a young girl, and her memory was interwoven into a different time frame and age for her" (Burgess et al., p. 16). Sadly, staff members minimized or ignored the reports of sexual abuse, and some even laughed as they watched the assault occur.

Because the replication of the dynamics associated with trauma has the potential to bring senior trauma survivors' pasts into their present, it is important that caregivers avoid or minimize the extent to which senior trauma survivors are exposed to situations that make them feel powerless, stigmatized, betrayed or retraumatized. This may be especially crucial to the well-being of senior trauma survivors who suffer dementia. Consistent with this, the Baycrest Centre for Geriatric Care (David \& Pelly, 2003) has published a practice manual regarding the care of senior Holocaust survivors. The content of the manual includes a discussion of the issues confronted by family members and health care professionals providing care to senior Holocaust survivors, including a detailed list of triggers that may elicit adverse reactions in senior Holocaust survivors and suggestions for how caregivers might respond. However, because the authors did not develop a higher order conceptual framework of the many examples they described, the applicability of their observations and suggestions to other types of trauma is unclear. To address this gap, Ammerman and Palmer (2005) conducted a qualitative analysis of David and Pelly's (2003) discussion of caring for aging Holocaust survivors (see Figure 1 
in Appendix A). This analysis identified six types of cues that may trigger one or more adverse reactions in senior Holocaust survivors, including cues from the Physical environment (e.g., which harsh smells, loud voices or sounds), various Structural conditions (e.g., group organizing, fixed routines and schedules), the Socio-cultural context (e.g., Jewish holidays, specific clothing or Christian symbols), Personal care and health issues (e.g., grooming, receiving injections or feeling ill), Personal questioning (e.g., requests for medical procedures or discussion of financial matters) and Internal psychological factors (e.g., reminiscence or nightmares about the Holocaust). These triggers may evoke explicit conscious or implicit nonconscious memories of seniors' traumatic experiences during the Holocaust (Kristiansen, 2004) and these memories may, in turn, promote various adverse emotional and behavioural reactions. The adverse emotional reactions noted in the manual include anxiety, depression, fear, distrust and anger, and behavioural reactions include seniors' refusal to listen, discuss or cooperate, hoarding, screaming, and moving away.

David and Pelly (2003) describe a Supportive Care Approach as useful when working with Holocaust survivors. In this approach, caregivers: 1) remove any triggers, if possible; 2) communicate with seniors during interactions (i.e., explain what they are doing and why); 3) provide seniors with choices (e.g., which shirt to wear); 4) accommodate behaviours or modify services to meet seniors' individual needs; 5) promote a trusting relationship by having personalized visits, listening to seniors' stories and being respectful of their wishes and rights; and 6) encourage the involvement of trusted family members and friends in the care of the senior. Two additional preventive measures described as minimizing the long-term impact of trauma involve adjusting the 
Physical Environment (e.g., avoiding locked areas, ensuring private spaces for residents and ensuring food is always available) and Structural Conditions (e.g., avoiding the use of wristbands for identification and lineups for services, and ensuring staff consistency).

Although the applicability of this model to other types of trauma is merely speculative, David and Pelly's (2003) practice manual for the caregivers of senior Holocaust survivors offers potentially important suggestions regarding the care of senior survivors of other types of trauma. Indeed, a number of David and Pelly's (2003) suggestions are consistent with the need to reduce senior trauma survivors' exposure to the dynamics associated with trauma, including providing choices that increase seniors' sense of control and power, being respectful in a way that ensures that seniors are not shamed or devalued, and working to establish a trusting, consistent relationship that is not characterized by betrayal.

\section{The Proposed Research}

Unfortunately, the staff of residential care facilities are typically not taught about the adverse effects of powerlessness, stigmatization, betrayal, and maltreatment on seniors in general and senior trauma survivors in particular. For example, textbooks used to teach future nurses with an interest in gerontology (e.g., Ebersole, Hess, \& Luggan, 2004; Miller, 2004; Stanley, Blair, \& Breare, 2005) do not discuss the long-term effects of trauma on seniors or the need for caregivers to avoid or minimize the extent to which senior trauma survivors are exposed to experiences that make them feel powerless, stigmatized, betrayed or retraumatized. Given this, as well as the increasing senior population, the prevalence of trauma in seniors' lives, and the long lasting effects of trauma, this research is designed to examine whether seniors in residential care facilities 
are exposed to the psychosocial dynamics associated with trauma, namely powerlessness, stigmatization, betrayal, and maltreatment. It is also designed to gain insight into the unique needs of senior trauma survivors in residential care, the issues and challenges they pose to residential workers, and how best to respond to these needs and issues in a way that facilitates the well-being of both senior trauma survivors and those who care for them. 


\section{METHOD}

\section{Participating Care Facilities}

To obtain diverse views and experiences regarding working with senior trauma survivors, the study began by purposively sampling (Dey, 1999) from the 32 long-term care facilities in the Ottawa-Carleton region. One facility was selected because it served a rural population, another was chosen because it was known to cater to senior trauma survivors, and a third facility was selected at random. When invited to have their staff participate in a survey of care providers' experiences with senior trauma survivors, the Directors of Care/Administrators of these three facilities responded affirmatively. They were also asked if they knew of any Directors of Care/Administrators at other facilities who might be interested in having their staff participate in this research, and this snowball sampling (Seale, 1999) resulted in the participation of three additional facilities.

In preliminary meetings, the purpose of the study was explained to each of the Directors of Care/Administrators and other administrative staff, and informed consent was obtained (see Appendix B for a copy of the research materials). To gain information about each facility, the six Directors of Care/Administrators completed a short questionnaire asking about the characteristics of the staff (i.e., number of people employed in 12 positions and percentage of employees who were part-time, full-time, and casual, and residents (i.e., number of residents, percent female, and ethnic/cultural background). The next section asked about any procedures or treatment options for senior residents with a history of interpersonal trauma. More specifically, they were asked whether, on admission, they explicitly made inquiries into a resident's history of interpersonal trauma (i.e., child abuse, rape or partner abuse, being a war veteran or 
concentration camp/Holocaust survivor), if the facility had any treatment resources for residents with psychological problems and residents who experienced interpersonal trauma earlier in life, and whether the facility provided any staff training regarding the effects of earlier life trauma.

\section{Care Workers' Survey}

A "Working with Senior Trauma Survivors in Residential Care Survey" was developed in several stages. A preliminary version of the survey was developed by the researchers, with feedback from the members of the thesis committee. This survey was then amended in view of the feedback of six gerontology-related professionals: three registered nurses, one of whom was a director of a government agency for the prevention of elder abuse, one whom was a geriatric nurse specialist and one whom was also the Director of Care at a long term care facility, a nurse's aide in a long term care facility, and two social workers employed in long term care facilities. Then, during the preliminary meetings mentioned above, the Directors of Care/Administrators and other administrative staff were invited to comment on the content and wording of the amended survey. This process resulted in a number of additional changes to the survey. In particular, a scale assessing care workers' attitudes toward senior trauma survivors was deleted to reduce the length of the survey, items assessing staff morale were deleted as their relevance to the study was questioned, and items assessing the behaviour of staff were reworded to assess the behaviour of staff, residents and/or visitors so as to make the survey more acceptable to administrators. The Director of Care/Administrator at each of the six facilities distributed a package containing an introductory letter describing the purpose of the study and the contents of the survey, the survey itself, and an envelope 
instructing participants to return the survey to a locked drop-off box (see Appendix B for a copy of the research materials).

The survey contained three sections. The first section assessed respondents' demographic (i.e., age, gender, education) and employment-related characteristics (i.e., job title, years working with seniors, gerontology training, training regarding the effects of trauma on people generally and seniors in particular), the next section asked about their experiences working with seniors in general, and the third section asked about their experiences working with senior trauma survivors in particular.

In the section labeled 'Experiences working with seniors,' care workers completed measures of their familiarity with the seniors they work with and how often they had seen senior residents being exposed to the psychosocial dynamics underlying interpersonal trauma. As a measure of their familiarity with the seniors they work with, care workers were asked to use 5-point scales to rate how often they receive and review a description of a new resident's life history, how well they get to know the seniors they work with, and how often they work with the same seniors each day/shift. To gain insight into senior residents' exposure to potentially traumagenic dynamics, care workers were asked to use 5-point scales to rate how often, in the past year, they had witnessed anyone (i.e., a visitor, another resident or a staff member) act in each of three ways that render residents powerless (i.e., made a decision on behalf of resident without asking the resident first, entered a resident's room with knocking or asking permission first, and 'ordered' rather than asked a resident to do something), committed each of three acts of betrayal (i.e., broke a resident's confidence, broke a promise because they forgot, and broke a promise because they ran out of time), and perpetrated verbal (i.e., insult, tease or 
swear at a resident or call a resident names, yell in anger at a resident, and talk to a resident as if s/he were a child), physical (i.e., grab, push or shove a resident, and slap, hit or kick a resident) and sexual abuse (i.e., touch a resident in a sexual way), as well as neglect (i.e., ignore a resident's needs or fail to do things for a resident in a timely or adequate fashion). Finally, because staff with more negative attitudes toward the seniors they care for may be more likely to treat residents in ways that make them feel devalued or shameful, participants' attitudes were assessed by asking them to use 7-point scales to rate the extent to which the seniors they work with are characterized by each of nine bipolar adjectives relevant to seniors in residential care (e.g., demanding/undemanding, cooperative/uncooperative, boring/interesting).

In the last section, labeled 'Experiences working with senior trauma survivors,' participants were asked if they ever worked with a senior who had experienced a trauma earlier in life. Those who answered positively were asked how many senior trauma survivors they worked with and what types of trauma these seniors were exposed to. As a measure of staffs' awareness of residents' earlier traumas, participants were asked what percentage of these trauma survivors had their trauma noted in files or records, and, using a 5-point scale, rated how often these seniors talked to them about their trauma. Caregivers were also asked to use a scale ranging from Never (0) to All the time (4) to rate how often these trauma survivors seemed to think about their traumas and to describe, in their own words, any particular things that seemed to make these trauma survivors think about their traumas.

To gain some insight into senior trauma survivors' well-being, staff were asked to use scales ranging from None (0) to All of them (4) to indicate how many of the senior 
trauma survivors in their care displayed each of ten symptoms of PTSD. Three of the symptoms assessed the intrusive symptoms of PTSD (i.e., acting like they were reliving their trauma; having recurring, upsetting memories or dreams about their trauma; got upset in situations similar to their trauma), three items referred to avoidance symptoms (e.g., seemed numb or like they had no emotions; seemed disconnected or detached from other people; tried to avoid thinking or talking about their trauma), and four items asked about hyperarousal symptoms (e.g., seemed nervous, tense or on edge; had trouble sleeping or concentrating; seemed moody or irritable; had angry outbursts). Participants were also asked to use scales ranging from None (0) to All of them (4) to indicate how many of the trauma survivors they worked with had dementia, and bipolar scales ranging from Much worse (-2) to Much better (+2) to rate senior trauma survivors' health, physical health, physical mobility, and social engagement relative to that of their same sex peers. Finally, staff were asked to describe, in their own words, whether senior residents' experiences of trauma seemed to have any other effects on their behaviour, moods and emotions and how they responded to these effects.

In the last part of this section, care workers were asked a series of open-ended questions designed to elicit information about the needs of both senior trauma survivors and the staff who care for them (e.g., 'When providing care or services to these trauma survivors, did they ever present you with any unique needs or special issues?' and 'Was working with these suspected or known senior trauma survivors ever difficult or challenging in any ways?'). Staff members' experiences and thoughts regarding ways of meeting these needs were also elicited (e.g., 'If yes, please describe any things that helped you deal with these unique needs and/or special issues:' and 'Can you think of 
things that could be done to make it easier for staff to work with senior trauma survivors?'). 


\section{RESULTS}

\section{Participating Facilities}

As shown in Table 1 (all Tables and Figures appear in Appendix A), the six participating facilities served between 100 and 240 residents, most of whom were female ( $M=73.5 \%$, range $=70$ to $80 \%$ female). The ethnic backgrounds of the clientele served by these facilities also varied. Three facilities catered to a 'mixed' clientele, including one that provided services to mostly immigrant seniors, two facilities reported having mostly white Anglo-Saxon residents, and one facility cared for seniors of 'European' descent. Thus, the participating facilities provided care to a variety of populations.

These facilities also varied in the characteristics of their employees. In particular, two facilities employed mostly full-time workers while three employed primarily parttime workers. Two facilities had more registered or licensed practical nurses than registered nurses while the other four facilities, which had equal numbers of practical and registered nurses, employed more personal support workers. Only one facility had any home support workers. Most employed only a few restorative care workers, although one facility reported having 15 . In general, the facilities employed between 0 and 3 occupational/physiotherapists and 0 to 7 recreational therapists. However, one facility employed 6 occupational/physiotherapists and 11 recreational therapists. The composition of the staff of these facilities, then, was quite varied.

As shown in Table 2, four of the six participating facilities (67\%) indicated that, on admission, they Never explicitly make inquiries into a resident's history of interpersonal trauma, while one facility indicated that they do this Sometimes and another reported that they do this Always. Although all of the Directors of Care/Administrators 
reported having treatment resources for senior residents with psychological problems, for 5 facilities this consisted of a psychogeriatric outreach team from a local hospital that visits once or twice a month or when needed to do assessments or provide counseling and for another facility it was a private practice geriatric psychiatrist who comes in once a week. Only one facility reported any in-house resources for senior residents with psychological problems, which consisted of some nurses with advanced preparation in psychogeriatric conditions. Only 2 of the 6 facilities (33\%) had treatment resources specifically for senior residents who experienced interpersonal trauma earlier in life. For one of these facilities this resource consisted of the outreach team from a local hospital and for the other facility it was a social worker who would address any issues by talking to the resident and/or their family. Finally, only 2 of the 6 facilities provided staff training regarding the effects of earlier life trauma on seniors. For one of these facilities this training consisted of the effects of abuse on the seniors in their care and for the other it involved staff in-service and training currently being conducted regarding resident abuse. This description, however, suggests that this staff training focused more on the abuse of seniors rather than the long-term effects of earlier interpersonal trauma.

In sum, the six facilities involved in this research were quite varied in terms of the characteristics of their residents, the nature of their staffing, and their trauma-related treatment and training resources.

\section{Participating Care Workers}

A total of 62 staff returned completed questionnaires, of whom $83.9 \%(n=52)$

were female. These participants consisted of 14 (22.6\%) Registered Nurses, $12(19.4 \%)$ Registered/Licensed Practical Nurses, 10 (16.1\%) Support Services Workers (e.g., 
housekeeping, kitchen, maintenance), 8 (12.9\%) Personal Support Workers, 4 (6.5\%) Health Care/Nursing Aides, 3 (4.8\%) Social Workers, 3 (4.8\%)

Occupational/Physiotherapists 2 (3.2\%) Recreational Therapists/Assistants, and $6(9.7 \%)$ occupying 'Other' positions including $3(4.8 \%)$ clerks, $2(3.2 \%)$ in management positions, and $1(1.6 \%)$ dietician. Two of the Registered Nurses also held managerial positions. Similarly, 2 of the Registered/Licensed Practical Nurses held other positions, including Home Support Worker and a managerial position. These respondents were between 21 and 64 years of age $(M=43.5, S D=12.1$ years $)$ and reported an average of 10.4 years working in a senior residential care facility $(S D=8.7$ years). Most were employed full-time $(62.9 \%)$, rather than part-time $(30.6 \%)$ or as casual workers $(6.5 \%)$. Most participants $(61.3 \%)$ reported being a college or university graduate, although their education ranged from less than high school (3.2\%) to holding a post-graduate degree (9.7\%). Thus, with the exception of gender, the characteristics of these participants were reasonably heterogeneous.

\section{Quantitative Findings}

\section{Preliminary Analyses}

Preliminary analyses were conducted to reduce the size of the quantitative data set and examine the possibility that participants' responses to the survey differed as a function of the facility they worked at.

Scale construction. To reduce the data, scale scores were calculated where appropriate. Specifically, the mean of participants' responses to the three items assessing their gerontology and trauma-related training was calculated as a measure of their overall training. Similarly, the mean of the Z-scores of participants' responses to the three items 
asking: 'How often do you get and review a detailed description of a new resident's life history,' 'How well do you get to know the residents you work with,' and 'How often do you work with the same residents each day/shift' was taken as an index of their overall familiarity with the residents they work with. ${ }^{2}$ The mean of participants' responses to the items assessing the frequency they witnessed instances of behaviours that might induce feelings of powerless and betrayal, their responses to the nine biplolar items measuring their attitudes toward the seniors they work with, and their responses to the frequency they witnessed acts of verbal and physical abuse were also calculated as overall measures of these constructs. Scale scores were similarly calculated for each of the three symptom clusters underlying PTSD. Using this approach, higher scores indicated more of the attribute in question and, for the attitude measure, more positive attitudes. Item analyses, shown in Table 3, revealed that each of these measures was internally consistent, with $\alpha$ s ranging from .68 to .90 .

Effects due to facility. A series of analyses was conducted to assess whether care providers' responses varied as a function of the facility they worked at. One-way Analyses of Variance (ANOVAS) revealed that Facility had a statistically reliable effect on 3 of the 24 continuous variables that were examined, namely workers' attitudes toward the seniors they work with, $F(5,53)=3.96, p<.01$, $e t a^{2}=.38$, the number of senior trauma survivors displaying avoidance behaviours, $F(5,39)=4.20, p<.01$, eta ${ }^{2}=$ .33 , and the frequency participants observed someone acting in a way that might make residents feel powerless, $F(5,54)=2.63, p<.05$, eta $a^{2}=.25$. Scheffe's post-hoc tests

\footnotetext{
${ }^{2}$ Participants' $Z$-scores, rather than their raw scores, were considered because two familiarity items used 5-point response scales while the third used a 4-point response scale.
} 
identified only one significant difference in respondents' attitudes toward the seniors they worked with: the workers from Facility $3(M=5.25, S D=0.78)$ had more positive attitudes than those from Facility $4(M=3.75, S D=1.17)$. In regard to the frequency avoidance behaviours, Scheffe's post-hoc tests indicated that the participants from Facility $5(M=2.22, S D=2.22)$ rated more senior trauma survivors as displaying avoidance behaviours than did the respondents Facility $1(M=0.67, S D=0.47)$ and Facility $2(M=0.73, S D=0.76)$. Finally, and despite the overall significant effect, Scheffe's post-hoc pair-wise comparisons failed to find any differences in the frequency of witnessing acts associated with powerlessness as a function of facility.

Chi-square tests indicated that only one of the 6 categorical variables was dependent on Facility, namely respondents' gender, $\chi^{2}=11.33, \mathrm{p}<.05$, Cramer's $\mathrm{V}=$ 0.43. Almost equal numbers of females and males from Facility 5 participated $(54.5 \%$ female) whereas respondents from the other 5 facilities were more commonly female than male $(M=82.1 \%$, range $=72$ to $99 \%$ female $)$.

Given that only 4 of the 30 analyses yielded significant effects due to Facility, and that these significant effects were not associated with any discernable pattern across facilities, the data of the respondents from all of the facilities were analyzed together. Experiences Working with Senior Residents

Gerontology and trauma-related training. Table 4 presents the descriptive statistics for these workers' gerontology and trauma-related training. On average, these respondents had between A little and A moderate amount of specialized gerontology and general trauma-related training or course work, but only A little training or course work regarding the long-term effects of earlier trauma on the well-being of people aged 65 or 
older. Stated differently, almost half of the participants had at most A little gerontology training ( $n=29,47.6 \%)$, two thirds had at most $A$ little general trauma-related training ( $n$ $=40,64.5 \%$ ), and three quarters had at most at $A$ little training regarding the long-term effects of earlier trauma on seniors $(n=48,77.4 \%)$.

Familiarity with residents. Table 5 presents the descriptive statistics for the measures of participants' familiarity with residents. On average, participants indicated that they Usually get and review a detailed description of a new resident's life history, that they get to know the residents they work with Fairly well, and that they work with the same residents each day/shift between Usually and Always. Stated differently, half of the participants at least Usually reviewed residents' life histories $(n=31,50 \%)$, three quarters got to know the residents they worked with at least Fairly well ( $n=48,77.4 \%)$, and two thirds Usually or Always worked with the same residents ( $n=3861.3 \%$ ).

Potentially traumagenic behaviour. Table 6 provides the descriptive statistics of workers' responses to the items asking how often in the past year they witnessed various potentially traumagenic behaviours. As shown there, on average these participants had witnessed someone enter a resident's room without knocking or asking permission and someone make a decision that affected a resident without consulting them $A$ few times in the past year. On average, they reported seeing someone 'order' a resident to do something rather than asking and explaining why between Once or twice and Afew times in the past year. Stated somewhat differently, these three behaviours that might make residents feel powerless were witnessed at least once in the past year by 78 to $84 \%$ of the participants. 
Participants also frequently saw someone act in ways that might make a resident feel betrayed. As shown in Table 6, on average these workers reported seeing someone, in the past year, break a promise to do something for a resident because they ran out of time $A$ few times, break a promise to do something for a resident because they forgot between Once or twice and A few times, and break a resident's trust by telling something they said they wouldn't tell Once. These acts of betrayal were witness at least once in the past year by 51 to $92 \%$ of the respondents.

In regard to verbal abuse, on average these workers reported witnessing someone, in the past year, talking to a resident as if s/he were a child between Once or twice and A few times, insult, tease or swear at a resident or call a resident names Once or twice, and yell in anger at a resident about Once. At least one instance of these behaviours was observed by 53 to $82 \%$ of the sample.

Physical abuse, sexual abuse and neglect were witnessed less frequently. On average, these care workers reported seeing someone, in the past year, grab, push or shove a resident at most Once, slap, hit or kick a senior resident at most Once, touch a resident sexually almost Never, and ignore a resident's needs or fail to do things for a resident in a timely or adequate fashion between Once and A few times. Stated differently, $30 \%$ of the participants reported seeing at least one instance of someone grabbing, pushing or shoving a resident, 19\% had seen someone slap, hit or kick a resident, $8 \%$ had seen someone touch a resident in a sexually inappropriate way, and $79 \%$ had seen at least one instance of neglect.

Finally, the descriptive statistics indicated that, on average, these participants had neutral or only slightly positive attitudes toward the seniors they worked with $(M=4.31$, 
$S D=1.04$ on a scale potentially ranging from 1 to 7 ). Given that respondents' scores were normally distributed around this neutral mean score, about $16 \%$ of the sample held at least moderately negative attitudes toward the seniors they cared for.

Summary. Overall, these respondents had relatively little gerontology and trauma-related training, were often only somewhat familiar with the residents they worked with and often had at least slightly negative attitudes toward the seniors they cared for. In addition, the vast majority of these workers reported witnessing a least one instance of someone acting in a way that might make a resident feel powerless or betrayed, the vast majority had seen a resident neglected, half had seen at least one act of verbal abuse, a third had seen at least one act or physical abuse and, although rarer, $8 \%$ had witnessed the sexual abuse of a resident. These findings suggest that a good number of senior trauma survivors in long-term care may be exposed to psychosocial dynamics that replicate those they experienced during their earlier traumatization. Conceivably, some of this exposure may stem from workers' lack of training regarding caregiving within the context of issues associated with trauma.

\section{Experiences Working with Senior Trauma Survivors}

Three quarters $(77.4 \%, n=48)$ of the respondents indicated that they had worked with at least one senior trauma survivor at some point during their career. These 48 participants had provided care to a median of between 11 and 15 senior trauma survivors $(M=16.49, S D=32.98$ senior trauma survivors $)$ and, as shown in Table 7, at least $84 \%$ of these workers had provided care to at least one combat veteran, someone who had been physically assaulted as an adult, someone who had been physically or sexually abused during childhood, or someone who had been held in a concentration camp. 
Working with a Prisoner of War (78\%) and someone who had been sexually assaulted as an adult $(62 \%)$ were also common.

On average, respondents indicated that About half of these trauma survivors had their trauma noted in their files or records $(M=1.90, S D=1.90)$. However, half of the participants $(n=24,50 \%)$ indicated that at most a few of these trauma survivors had their traumas noted in their files or records. On average, participants indicated that senior trauma survivors talked to them about their trauma just over Once or twice $(M=1.31, S D$ $=0.85$ times) and three-quarters indicated that these trauma survivors spoke about their traumas at most Once or twice.

Trauma survivors' well-being. On average, these care providers reported that the senior trauma survivors they worked with thought about their trauma between Sometimes and Often $(M=2.32, S D=0.73$ times $)$, with a third of these care providers $(n=17$, $37.1 \%$ ) reporting that the senior trauma survivors thought about their trauma Often or All the time. Indeed, only $6.8 \%(n=3)$ of those who worked with a trauma survivors said they Never or Rarely thought about their trauma On average, respondents reported that thinking about their trauma made senior trauma survivors feel Somewhat worse $(M=$ $1.16, S D=0.91$ ), with the vast majority reporting that thinking about their trauma made senior trauma survivors feel at least Somewhat worse $(n=29,70.7 \%)$. Although $29.0 \%$ reported that thinking about their trauma made senior trauma survivors feel About the same or Somewhat better $(n=12)$, no one indicated that thinking about their trauma made senior trauma survivors feel Much better.

Table 8 displays the descriptive statistics for care workers' ratings of the number of senior trauma survivors suffering from symptoms associated with PTSD. In regard to 
Other indicators of trauma survivors' health assessed in the survey included ratings of how many suffered from dementia and their overall health, physical mobility, and social activity. On average, these participants indicated that About half of the senior trauma survivors they worked with had dementia $(M=2.26, S D=1.16)$. As displayed in Table 9, on average these staff members rated both senior trauma survivors' overall health and their physical mobility as between Somewhat worse and About the same as that of other residents, with almost half rating senior trauma survivors' overall health (46.7\%) and physical mobility (43.5\%) as at least Somewhat worse than that of other, nontraumatized, residents. Finally, on average these care workers rated senior trauma survivors' social health as Somewhat worse than that of other residents, with three quarters $(73.3 \%)$ rating senior trauma survivors' social activity as at least Somewhat worse than that of residents who had not experienced an interpersonal trauma.

Summary. Overall, three quarters of participants worked with a senior trauma survivor of whom many were combat veterans, were physically assaulted as adults, or were physically or sexually abused during childhood. About half had this trauma noted in their files or records, although most senior trauma survivors tended not to talk about their past trauma to care workers. They did, however, think about their trauma at least sometimes and felt worse when they did so, as reported by staff members. Care workers also indicated that between a few and half of senior trauma survivors experienced the PTSD symptom clusters of hyperarousal, avoidance, and intrusive experiences. About half of senior trauma survivors had dementia and, on average, staff members rated both senior trauma survivors' overall health and their physical mobility as between Somewhat 
the three intrusive symptoms assessed in the survey, $54.5 \%$ of the care workers reported that at least half of the senior trauma survivors they had worked with got upset in situations similar to their trauma, $35.5 \%$ reported that at least half had upsetting memories or dreams about their trauma, and $22.2 \%$ reported that at least half acted like they were reliving their trauma. On average, respondents indicated between $A$ few and About half of the senior trauma survivors they worked with displayed intrusive experiences. Of the three avoidance behaviours assessed in the survey, 55.8\% reported that at least half avoided talking about their trauma, $35.6 \%$ reported that at least half seemed disconnected or detached from other people, and $18.2 \%$ reported that at least half seemed numb or like they had no emotions. For the four measures of hyperarousal, $56.6 \%$ of the participants indicated that at least half of the senior trauma survivors they had worked with seemed nervous, tense, or on edge, $51.1 \%$ reported that at least half seemed moody or irritable, $50.0 \%$ reported that at least half had angry outbursts, and another $50.0 \%$ reported that at least half had trouble sleeping or concentrating. On average, these respondents indicated that between $A$ few and About half of the senior trauma survivors they worked with displayed behaviours indicative of intrusive experiences, avoidance and hyperarousal. However, a repeated measures ANOVA was significant, Pillai's Trace $V=.290, F(2,42)=8.56, \eta^{2}=0.29, p=.001$. Bonferroni corrected comparisons revealed that participants regarded hyperarousal symptoms as more common among senior trauma survivors than either intrusive experiences (mean difference $=0.38, p<.01$ ) or avoidance symptoms, $($ mean difference $=0.42, p<.01$ ), which were rated as equally common among senior trauma survivors (mean difference $=$ $0.04, n s)$ 
worse and About the same as that of other residents, and their social health as Somewhat worse than that of residents who had not experienced an interpersonal trauma.

\section{Correlational Analyses}

Two-tailed correlations were calculated to examine the relations between participants' training, familiarity and attitude scores with the frequency they witnessed traumagenic dynamics, the number of trauma survivors they worked with and the measures of senior trauma survivors' well-being. Before conducting these analyses, however, variables with positively skewed frequency distributions were transformed. Specifically, total verbal abuse scale scores and the item asking how often respondents had witnessed someone ignoring a resident's needs or failing to do something for a resident in a timely fashion were both squared to obtain a normal distribution. Participants' total physical abuse scores and their responses to the item asking how often they had witnessed someone touch a resident in a sexual way were also positively skewed. However, because the vast majority of participants gave the same or similar responses, adequate transformations could not be found. The findings from the analyses involving these variables should therefore be interpreted with caution.

The first set of correlational analyses examined the extent to which workers' training and their familiarity with and attitudes toward the residents they worked with were related to the frequency they witnessed residents being exposed to the dynamics associated with trauma and the number of trauma survivors they worked with. As shown in Table 10, respondents with more training, regardless of type, reported being more familiar with the residents they worked with and witnessing more instances of overt physical and sexual abuse. Participants who were more familiar with the residents they 
worked with reported seeing moderately more acts of betrayal and inappropriate sexual touching. They also tended to witness more acts of physical abuse and fewer acts of neglect. Respondents with more positive attitudes toward the residents they worked with, on the other hand, reported witnessing moderately more acts associated with powerlessness, betrayal and verbal abuse, and marginally more instances of physical and sexual abuse. Interestingly, workers who were more familiar with the residents they cared for held marginally less positive attitudes toward them than those who were less familiar with the residents they worked with.

The next set of correlational analyses was limited to the data of the 48 workers who had worked with at least one trauma survivor. As shown in Table 11, these analyses indicated that respondents with more training, regardless of type, rated senior trauma survivors as socializing more. Those with more training regarding trauma in general or senior trauma survivors in particular rated more trauma survivors as having intrusive experiences and displaying hyperarousal while those with more training regarding senior trauma survivors indicated that traumatized seniors talked marginally more about their traumas and that more senior trauma survivors displayed avoidance behaviours. Thus, more training regarding the impact of earlier trauma on seniors was associated with seniors more frequently talking about their traumas, less positive ratings of senior trauma survivors' psychological well-being, and more positive ratings of their social well-being.

The correlations in Table 11 also indicate that respondents who were more familiar with the residents they cared for described senior trauma survivors as more often talking more about their trauma and as marginally more likely to have avoidance and hyperarousal symptoms. Finally, respondents with more positive attitudes toward the 
seniors in their care indicated that moderately fewer trauma survivors displayed avoidance and hyperarousal symptoms and marginally fewer suffered dementia.

Summary. While care workers who had more training, regardless of type, were more familiar with the residents they worked with, they also tended to hold more negative attitudes toward these seniors. Care workers with more training, particularly trauma-related training, and those who were more familiar with the residents they worked with were at least marginally more likely to report witnessing some form of overt physical abuse and inappropriate sexual touching in the past year. In addition, those with less favourable attitudes toward the residents they cared for reported witnessing at least marginally more instances of residents being exposed to acts than might make them feel powerless or betrayed and acts of verbal, physical and sexual abuse.

Among the 48 workers with experience working with senior trauma survivors, those with more trauma-related training and those more familiar with the residents they worked with indicated that senior trauma survivors spoke at least marginally more frequently about their traumas and that at least marginally more trauma survivors displayed symptoms associated with PTSD. In addition, those with less positive attitudes toward the seniors they worked with indicated that more trauma survivors displayed the avoidance and hyperarousal symptoms of PTSD, while marginally fewer had dementia.

\section{Additional Analyses}

Additional analyses were conducted to examine the impact of the extent of participants' contact with residents on the variables assessed in this study. Analyses were also conducted to examine whether any demographic characteristics might provide alternative explanations for any of the significant correlations reported above. 
Contact. Participants were categorized as 'behind-the-scenes' workers if they worked in a position not requiring direct contact with residents. This included 10 support services workers and 3 clerks $(n=13)$. Participants were categorized as 'front-line' workers if they worked in a position requiring direct contact with residents. This included all other staff members in all other positions who participated in this study $(n=$ 49). As displayed in Tables 12 and 13, compared to behind-the-scenes workers front-line workers had more gerontology training (i.e., A moderate amount vs. A little), more training regarding the effects of trauma on people generally (i.e., A little to A moderate amount vs. None to A little), and more training regarding the effects of trauma on seniors (i.e., A little vs. None). Relative to behind-the-scenes workers, front-line workers were also more likely to review residents' histories (i.e., doing so between Sometimes and Usually vs. between Not at all and Rarely), came to know residents somewhat better (i.e., Fairly well vs. A little to Fairly well), and more frequently worked with the same residents (i.e., Usually vs. Rarely). Relative to behind-the-scenes workers, front-line workers also reported witnessing more instances of acts that might make senior residents feel betrayed (i.e., Once or twice to A few times vs. Once or twice). Finally, relative to front-line workers, behind-the-scenes workers reported working with seniors who socialized less often with other residents (i.e., Much less vs. Somewhat less). However, the extent of workers' contact was independent of their attitudes toward residents and all of the trauma-related measures.

These findings suggest that the extent of participants' contact with residents may account for the marginal relation observed between the extent of workers' trauma-related training and witnessing betrayal, as reported in Table 10. To assess this possibility, 
partial correlations were calculated between the extent of workers' general trauma-related training and the frequency they observed acts of betrayal while controlling for contact. This relation became nonsignificant, $r=.11, n s$. Thus, workers with more training regarding the effects of trauma on people in general may have witnessed more acts consistent with betrayal simply because they had more direct contact with senior residents.

Demographic correlates. Table 12 presents the correlations of participants' gender, age, education, years' experience and worker status with their scores on the predictor (i.e., measures of training, familiarity, attitudes) and criterion variables (i.e., measures of traumagenic dynamics and trauma-related variables). As shown there, only participants' age was systematically associated with both a predictor and a criterion variable involved in a significant relation. Specifically, older participants were moderately less likely to have training regarding the effects of trauma and were marginally less familiar with the seniors they cared for. Older participants also reported witnessing significantly fewer instances of physical abuse and marginally fewer instances of sexual abuse. These findings suggest that participants' age may account for the observed relations between trauma training and witnessing physical and sexual abuse. To assess this possibility, partial correlations were calculated between the extent of workers' general trauma training and the frequency they observed physical and sexual abuse while controlling for age. While the extent of general trauma training and the frequency of witnessing sexual abuse remained significant after controlling for age, $r=.28, p<.05$, the relation between general trauma training and witnessing physical abuse became nonsignificant, $r=.25, n s$. Thus, participants' age may account for the observed relation 
between general trauma training and the frequency of witnessing physical abuse. Rather than the relation between trauma training and frequency of witnessing physical abuse being spurious, however, it is conceivable that older participants witnessed more physical abuse because their trauma training increased their sensitivity to such abuse.

\section{Qualitative Findings}

Participants' responses to the open-ended questions provided an opportunity to gain a richer understanding of the issues and challenges faced by those caring for senior trauma survivors. Because these 11 questions asked specifically about working with senior trauma survivors, only the 48 respondents who had worked with at least one senior trauma survivor provided responses.

Suspecting trauma. When asked to describe the things that made them suspect a senior resident had experienced an interpersonal trauma earlier in life, the 31 participants who responded pointed to one or more of the symptoms associated with PTSD. Table 14 lists the frequency these symptoms were mentioned and illustrative quotes. As shown there, the majority of participants $(71.0 \%)$ suspected a history of trauma when a resident displayed behaviour that might be associated with reexperiencing a trauma, particularly residents' being distressed at exposure to cues that might resemble a trauma, followed by residents acting as if a trauma were recurring, most notably during personal care, repeatedly recalling the event, and having nightmares. Almost a quarter of the respondents $(22.6 \%)$ suspected a history of trauma when a resident tried to avoid stimuli that might be associated with a trauma, including efforts to avoid personal care and avoiding talking about the past. Participants also described signs of increased arousal as 
making them suspect a history of trauma $(16.1 \%)$, such as irritability or outbursts of anger, difficulty sleeping, and an exaggerated startle response.

The majority of these respondents $(71.0 \%)$ also cited one of more of the associated features of PTSD or the symptoms associated with Disorder of Extreme Stress Not Otherwise Specified as suggesting a trauma history. These included negative affect such as depression and sadness, distrust and paranoia, being withdrawn, negative selfappraisals, and a need for control/predictability.

Other effects of trauma. When asked if the senior trauma survivors' experiences of trauma had any effects on their behaviour, moods or emotions other than those already listed in quantitative section of the survey, $87.1 \%$ of the 31 respondents who answered mentioned one or more of the associated features of PTSD or the symptoms associated with Disorders of Extreme Stress Not Otherwise Specified. As shown in Table 15, these symptoms included negative affect, distrust, being withdrawn, aggressive behaviour, negative self-appraisals, and somatization. A third (32.3\%) of the participants mentioned one of more symptoms of increased arousal, including irritability, outbursts of anger and difficulty sleeping, while $19.4 \%$ wrote of traumas survivors' efforts to avoid activities and people associated with their trauma and $6.5 \%$ mentioned trauma survivors reexperiencing their traumas. Although not mentioned in their earlier responses, $12.9 \%$ of the respondents also described trauma survivors as having problematic attachment, including clinging to one staff member and not wanting to be alone.

Triggers to thinking about trauma. Table 16 lists participants' responses to the question asking them to describe any particular things that made senior trauma survivors think about their traumas. As shown there, most of the 38 participants who responded 
$(65.8 \%)$ described invasive procedures associated with personal care such as bathing and medical procedures such as injections. Over one-third of the participants (36.8\%) reported that the media, including movies and the news, had the potential to trigger trauma survivors' memories, as did people who were similar to the trauma perpetrator (36.8\%) and characteristics of the physical environment (31.6\%), such as darkness, loud noises and alarms. Less commonly mentioned triggers were psychological factors (15.8\%) such as nightmares, reminiscing and loneliness, facility routines (13.2\%) such as staff doing nightly checks or having to line up in hallways, special events and anniversaries (13.2\%) such as Remembrance Day and Jewish holidays, old songs (10.5\%), and conversations (10.5\%), including both what is said and the tone of voice.

Factors affecting trauma survivors' well-being. The responses of the 44 participants who answered one of the remaining 8 questions were redundant and were therefore pooled to avoid overlap. These 44 participants commented on factors affecting senior trauma survivors' well-being, including those that facilitate their well-being, those that detract from their well-being, and care workers' burden. Figure 2 in Appendix A illustrates the factors participants related to senior trauma survivors' well-being, as well as their interrelations.

As listed in Table 17, the respondents described various external, internal and interpersonal resources, as well as ways of caring, that could enhance trauma survivors' well-being. Almost half of the participants $(N=22,50.0 \%)$ described at least one external resource, such as outside support in the form of external counseling for the residents through a psychogeriatrician, being followed up by medical professionals, and staff training regarding the long-term effects of trauma on seniors. Several specific types 
of training were mentioned, including negotiation skills, time management, knowledge of proper care and procedures, information regarding ways of dealing with trauma survivors, information regarding the signs and symptoms of abuse and violence, and training to know when to refer to expert counseling.

Internal resources were also frequently described as contributing to senior trauma survivors' well-being $(N=19,43.2 \%)$. The most frequently mentioned internal resource was adequate staffing, including having better staff/resident ratios and having sufficient numbers of female staff. Medical resources were also deemed necessary, such as having medication to calm residents.

Almost a third of the respondents $(N=14,31.8 \%)$ described interpersonal resources that might contribute to the well-being of senior trauma survivors in residential care. These resources included positive relationships with family members so that family members could be asked for suggestions regarding the care of a senior trauma survivor and, at times, asked to attend during particularly difficult tasks. These interpersonal resources also included good inter-staff relations conducive to sharing information regarding useful caring techniques, triggers, and ways of avoiding triggers.

The vast majority of participants $(N=41,93.2 \%)$ also suggested positive ways of caring for senior trauma survivors. The most frequently mentioned of these involved communication, including listening, encouraging dialogue, explaining tasks and actions before doing them, speaking respectfully by, for example, referring to residents as Mr. and Mrs., asking the resident's permission to do care, and maintaining boundaries by letting residents know when their behaviour is disruptive. Many respondents also described reassuring the resident as a positive way to care for senior trauma survivors, 
and indicated that senior trauma survivors could be reassured by being patient, providing a sense of security, providing personal attention, and encouraging progress.

Many participants also wrote of the need to prevent triggers that provoke traumatic memories and/or disruptive behaviours. Ways of preventing triggers in the physical environment included providing a quiet and calm atmosphere, leaving the lights on 24 hours a day, and leaving doors ajar. Other ways of preventing triggers involved working slowly or at the resident's own pace, avoiding special events such as Remembrance Day celebrations, using special care when bathing, minimizing senior trauma survivors' access to trauma-related media coverage, allowing personal space, and avoiding topics of conversation such as war, death, and murder.

Over one quarter of the respondents described the need for staff to become familiar with residents' histories $(N=15,34.1 \%)$, including the need to know residents' trauma and family histories and factors that might act as triggers. Individualized care was also mentioned $(N=10,22.7 \%)$, including implementing individual strategies for each resident, and allowing the resident to be included in the decisions regarding their care. Other positive ways of caring included redirecting the resident's attention through activities and organized outings $(N=7,15.9 \%)$, and adopting a team approach that encourages team staff discussions and care-mapping $(N=7,15.9 \%)$.

As listed in Table 18, most respondents $(N=31,70.4 \%)$ described at least one factor that could detract from senior trauma survivors' well-being, typically by contributing to the development of the symptoms associated with PTSD. These included exerting power over residents by forcing care on them despite their resistance or forcing residents to talk about their traumas, acting unpredictably by rushing their care, sneaking 
up on them or acting suspiciously by whispering, abusing the resident either physically or verbally or with a punitive or judgmental demeanor, putting residents in situations that might trigger traumatic memories, and brushing off their experiences by denying what they are feeling or telling them to forget the past.

Finally, and as outlined in Table 19, almost half of the respondents $(N=19$, 43.2\%) described the personal burden they experienced as a result of caring for senior trauma survivors. Many staff members mentioned uncertainty as contributing to their personal burden, including being unsure of a situation, having difficulty gauging the mood of senior trauma survivors, not knowing what might trigger a traumatic memory, and not knowing how to help them. Respondents also mentioned being frustrated working with untrained, uneducated coworkers and being abused by the residents as contributing to their burden, burden that was characterized by feelings of guilt, self-blame and physiological stress. 


\section{DISCUSSION}

According to the current findings, many seniors residing in long-term care facilities have experienced some form of interpersonal trauma. For example, over threequarters of the 62 participants indicated that they had cared for at least one senior trauma survivor. Moreover, on average those who had worked with a trauma survivor indicated caring for as many as 17 trauma survivors. Despite these numbers, trauma survivors in long-term care appear to be vulnerable to being exposed to a number of trauma-related stimuli. Consistent with the frequency of discourse that renders seniors powerless observed in other studies (e.g., Wood \& Kroger, 1993; Grainger, 1993; Nussbaum, 1993), the vast majority of staff reported witnessing several instances of behaviours that might leave a resident feeling powerless. The vast majority of staff also reported witnessing at least one instance of a behaviour that might leave a resident feeling betrayed. Further, and as observed by other researchers (e.g., Campbell, 1971), almost half of the participants had at least slightly negative attitudes toward the seniors they cared for.

Moreover, senior trauma survivors in long-term care also appear to be vulnerable to feeling powerlessness, betrayed and shamed as a result of their exposure, either directly or vicariously, to overt maltreatment. For example, $31 \%$ of the staff members reported witnessing someone grab, push, or shove a resident at least once in the past year, a rate that is consistent with the $36 \%$ of nursing personnel who reported witnessing at least one act of physical abuse in Pillemer and Moore's (1989) study. In addition, as many as $82 \%$ reported witnessing at least one instance of verbal abuse, including infantalizing 'elderspeak' (Grainger, 1993; O'Connor \& St. Pierre, 2004), 79\% reported witnessing at least one instance of neglect, and $8 \%$ reported witnessing at least one 
instance of sexual abuse in the past year. Given the secrecy surrounding abuse, particularly sexual abuse (Finkelhor \& Browne, 1985; Summit, 1983), and previous research suggesting that some nursing home staff minimize and ignore the sexual abuse of senior residents (Burgess, Dowdell, \& Prentky, 2000), it is conceivable that these observed rates underestimate the actual rates of abuse and neglect in long-term care facilities.

Participants also described senior trauma survivors as being exposed to a diverse array of trauma-related stimuli. Consistent with the triggers described in the manual on caring for aging Holocaust survivors distributed by the Baycrest Centre for Geriatric Care (David \& Pelly, 2003), these stimuli included invasive procedures associated with personal and medical care, media coverage of events that parallel a trauma, people who in some way resemble an abuse perpetrator (e.g., men or medical staff), characteristics of the physical environment such as darkness and loud noises, psychological factors such as nightmares, reminiscence and loneliness, facility routines such as nightly checks with flashlights, trauma-related events such as Remembrance Day, hearing old songs, and the trauma-related content and tones of conversations.

In view of the diversity and number of trauma-related stimuli, as well as the frequency of the psychosocial dynamics of trauma in long-term care facilities, it is not surprising that senior trauma survivors in residential care think about their traumas at least sometimes. Further, the extent of senior residents' exposure to trauma-related stimuli is important given that, on average, care workers rated thinking about trauma as making senior residents feel somewhat worse. Indeed, in their open-ended responses workers noted that the symptoms associated with PTSD were triggered by senior 
residents thinking about their earlier traumas and, in the quantitative section of their survey, half of the respondents indicated that at least half of the senior trauma survivors in their care had intrusive experiences of their trauma, displayed various avoidance behaviours, and were hyperaroused. In addition, almost three quarters of the staff members who responded to the open-ended questions mentioned trauma survivors having symptoms consistent with the diagnosis of Disorders of Extreme Stress Not Otherwise Specified or Complex PTSD (Herman, 1992; Roth et al., 1997; van der Kolk, 1996; van der Kolk et al., 1996). These symptoms included experiencing negative affect such as depression, being distrustful and even paranoid, being isolated and withdrawn, having negative self-appraisals such as low self-esteem and engaging in self-blame, and a heightened need for a sense of control and predictability.

Further, the participants in this study also described senior trauma survivors as having somewhat poorer physical and social well-being relative to their nontraumatized peers. Thus, as suggested by the findings of other studies (e.g., Baider et al., 1992; Coffey et al., 1996; Hazzard, 1993; Leskela et al., 2002; Wickett \& Kristiansen, 2005), including experimental studies (e.g., Langer \& Rodin, 1976), exposure to trauma-related stimuli may well detract from the psychological, physical and social well-being of senior trauma survivors in residential care. Indeed, because participants described half of the senior trauma survivors they worked with as having dementia, which may impede trauma survivors' ability to control their reactions to trauma-related stimuli (Grossman et al, 2004; Johnston, 2000; Mittal et al, 2001; van Achterberg et al., 2001), senior trauma survivors in residential care may be especially vulnerable to the detrimental effects of trauma-related stimuli on health. 
These findings concerning the potential frequency of senior trauma survivors' exposure to trauma-related stimuli and their well-being are, in themselves, disheartening, but they are especially disheartening given the apparent lack of treatment resources dedicated to trauma survivors in long-term care. Indeed, despite the detrimental psychological, physical and social effects attributed to trauma by these long-term care staff, and consistent with the neglect of trauma in gerontological nursing textbooks (e.g., Ebersole et al., 2004; Miller, 2004; Stanley et al., 2005), the majority of care workers, including front-line care workers, had little training regarding the effects of trauma on people in general or seniors in particular. Further, only the facility that catered to a traumatized population routinely inquired into trauma during intake, had treatment resources for both psychological problems generally and those associated with trauma in particular, and had staff training regarding the implications of earlier life trauma on the care of seniors.

Although seniors' histories of trauma are not routinely assessed at intake, staff may nevertheless become aware of such histories in the course of providing care. For example, on average front-line staff indicated that about half of the trauma survivors they worked with had their traumas noted in their files, files that they almost usually read. In addition, front-line staff indicated that, on average, they usually worked with the same residents each day/shift and came to know the residents they worked with fairly well. Further, on average the trauma survivors they worked with spoke to them about their trauma once or twice. Nevertheless, participants' open-ended responses included statements indicating that some senior trauma survivors became defensive in response to 
questions asking about their pasts and avoided talking about the past, suggesting that some residents' histories of trauma may remain unknown.

Staff members with more trauma-related training reported being more familiar with the residents they cared for, and both the extent of staff members' trauma-related training and their familiarity with residents were correlated with a number of traumarelated measures. In particular, staff members with more trauma-related training and those more familiar with residents described more senior trauma survivors as suffering from the intrusive, avoidance and hyperarousal symptoms of PTSD. These relations may have occurred because staff members with more trauma-related training were assigned to care for residents with more complex needs, including trauma survivors with PTSDrelated symptoms, providing such care may have required greater familiarity with residents. Both staff with more trauma-related training and those more familiar with residents also reported that residents more frequently spoke to them about their traumas, conceivably because residents perceived staff with trauma-related training as more receptive to such information and/or because they felt more comfortable with familiar staff. Finally, staff with more trauma-related training and those more familiar with residents reported witnessing more acts of betrayal and more instances of physical and sexual abuse. These relations may have occurred because staff members' trauma-related training increased their sensitivity to the maltreatment of residents.

However, both staff with more trauma-related training and those more familiar with residents reported moderately more negative attitudes toward the residents they cared for. As noted earlier, similar paradoxical findings have been reported by others (e.g., Hefner, 2001), although not everyone (e.g., Kite et al., 2005; Snape, 1996). 
Because both participants with more trauma-related training and those with more negative attitudes toward residents described more trauma survivors as suffering from the avoidance and hyperarousal symptoms of PTSD, it is possible that staff with more training may have more negative attitudes toward residents because they cared from more trauma survivors exhibiting difficult behaviours. This explanation seems particularly feasible given that avoidance behaviours (e.g., resisting care) are likely to make residents less cooperative while symptoms of hyperarousal (e.g., outbursts of anger; difficulty sleeping) may make trauma survivors' care more demanding. Moreover, the attitude measure included items assessing perceptions of residents' being cooperative and demanding. This interpretation is also consistent with Haight, Christ, and Dias' (1994) observation of negative attitudes on the part of staff who cared for seniors in poorer health, as is the fact that the correlation between the amount of trauma-related training and attitudes was rendered nonsignificant when participants ratings of the frequency of senior trauma survivors' intrusive, avoidance and hyperarousal symptoms were controlled statistically, $r=-.06$. Nevertheless, future research might usefully examine whether workers with negative attitudes are emotionally exhausted caring for senior trauma survivors in the same way as those who care for cognitively impaired residents (Novak \& Chappell, 1994).

Finally, participants' open-ended comments have implications for the types of resources available to senior survivors of trauma and provided by long-term care facilities. In particular, the present findings suggest the need for increases in the number of long-term staff (i.e., to allow for more time to attend to senior trauma survivors' greater needs), especially the number of female staff (i.e., to meet the needs of survivors 
of violence against women and children). Respondents also suggested that long-term care facilities routinely assess residents' histories of trauma at intake, act to facilitate relationships with residents' families so that their assistance can be solicited when necessary, and act to facilitate staff relations and teamwork conducive to sharing information regarding useful caring techniques, triggers, and ways of avoiding triggers

Regular access to a psychogeriatrician familiar with the impact of trauma on seniors to counsel residents was also recommended, as was the provision of staff training regarding trauma. Such training might inform workers of the frequency of trauma in seniors' lives, the effects of trauma on seniors (e.g., the symptoms of PTSD and Complex PTSD), things that might trigger seniors' memories of trauma, and positive approaches to caring for senior trauma survivors. In addition, such training might endeavour to make staff aware of the dangers of misattributing senior trauma survivors' symptoms of PTSD to dementia (Cooper, 2002), which may result in senior trauma survivors receiving inappropriate medications or having their realities denied. Also relevant are the positive procedures and approaches cited by participants, which included ways of preventing triggers, communicating with residents, providing reassurance, and providing individualized care. Education regarding the psychosocial dynamics underlying interpersonal trauma and their effects on well-being, as well as training regarding ways of preventing both such dynamics, along with education regarding other approaches described as detracting from senior trauma survivors' well-being (e.g., using force, acting unpredictably, being abusive or punitive and denying their experience) would also be useful. 
Many of the above recommendations appear in David and Pelly's (2003) manual regarding the care of aging Holocaust survivors, including the importance of communicating to senior trauma survivors, the benefits of involving family members and friends in residents' care, and the features of the physical and structural environment that may trigger senor trauma survivors' memories and/or adverse reactions. However, the current research also suggests that senior survivors of violence against women and children may present caregivers with some unique challenges. These factors include their need for personal space, the need for female health care aides, and their resistance to intimate, personal care. These issues call for trauma-related staff training that goes beyond war-related trauma to include the issues associated with violence against women and children. Indeed, the need for training regarding issues associated with violence against women and children may be especially great given the historical stigma that contributes to senior women's reluctance to disclose their experiences of sexual assault or partner abuse and the fact that most of the residents in long-term care facilities are women $(73.5 \%$ in the present study).

Finally, and as observed by Palmer (2005) in her interviews with people caring for senior trauma survivors with dementia, participants described caring for traumatized seniors as a personal burden. This burden stemmed from their uncertainty regarding ways of best caring for senior trauma survivors, the frustration they experienced dealing with uneducated coworkers, and their experiences of being abused by residents, and was characterized by feelings of guilt, self-blame and physiological stress. Because such personal burden may pave the way for the use of abusive management techniques, including overt abuse (Coyne, Reichman, \& Berbig, 1993; Pillemer \& Moore, 1989), 
efforts to alleviate such burden are likely to foster the well-being of not only staff members, but also that of senior trauma survivors in residential care. Thus, traumarelated training might usefully inform staff of the negative consequences of their work and encourage them to engage in appropriate self-care strategies.

In sum, the findings of this research suggest that a good number of the residents in long-term care have experienced some form of interpersonal trauma and that these traumatic experiences may have adverse effects on their psychological, physical and social well-being. The findings also suggest that the social interactions in long-term care facilities are frequently characterized by the psychosocial dynamics associated with interpersonal trauma, including interactions that may induce feelings of powerlessness, betrayal, and stigma or shame. Fortunately, however, the participants in this research suggested a number of ways of facilitating the well-being of senior trauma survivors in residential care, including the implementation of routine inquiry into trauma during intake, ready access to psychological treatment resources, and staff training regarding the implications of earlier life trauma on the care of seniors. Moreover, the fact that the number of trauma survivors participants worked with did not vary as a function of facility suggests that all of the facilities might benefit from trauma-related procedures, treatment resources, and staff training.

Like all research, however, the current study has both limitations and strengths that affect the reliability of the data and the validity of these findings and suggestions. The use of multi-item measures of the constructs assessed in the quantitative portion of the survey (e.g., the measures of training, familiarity, attitudes toward seniors, PTSD symptoms, and most of the potentially traumagenic behaviours) should go some way to 
ensuring their reliability. The convergence of the quantitative and qualitative findings (e.g., those associated with trauma survivors' symptoms) also suggests that participants' responses were reliable. A salient challenge to the validity of the findings, however, stems from the low participation rate at each facility, which was likely due to the length of the survey relative to the demands of care. Still, that care workers from six different facilities participated in this study and that their responses that did not differ as a function of facility suggest that the findings may well have some external validity. That participants' responses were largely independent of their demographic characteristics also speaks to the generality of these findings. Nevertheless, the correlational nature of this study obviates the possibility of causal conclusions. Thus, the validity of causal claims, such as those regarding the positive effects of trauma-related training on the quality of care or staff burden, cannot be established without at least quasi-experimental research. In view of the increasing senior population (Statistics Canada, 2002a, 2002b) and the number of seniors exposed to some type of interpersonal trauma, such research is obviously called for. 


\section{REFERENCES}

Aarts, P.G., \& Op den Velde, W. (1996). Prior traumatization and the process of aging: Theory and clinical implications. In B.A. van der Kolk, A.C. McFarlane, \& L. Weisaeth (Eds.), Traumatic stress: The overwhelming experience on mind, body, and society (pp. 359-377). New York: Guilford Press.

Allers, C.T., Benjack, K.J., \& Allers, N.T. (1992). Unresolved childhood sexual abuse: Are older adults affected? Journal of Counselling and Development, 71, 14-17. Allport, G.W. (1954). The nature of prejudice. Cambridge, MA: Addison-Wesley. American Psychiatric Association (1994). Diagnostic and statistical manual of mental disorders (4th ed.). Washington, DC: Author.

American Psychiatric Association. (2000). Diagnostic and statistical manual of mental disorders (4th ed. Rev.). Washington, DC: Author.

Ammerman, D., \& Palmer, A. (2005). A qualitative analysis of David and Pelly's (2000) practice manual: Caring for aging Holocaust survivors. Unpublished manuscript, Carleton University, Ottawa.

Axelrod, S., \& Eisdorfer, C. (1961). Attitudes toward old people: An empirical analysis of the stimulus-group validity of the Tuckman-Lorge questionnaire. Journal of Gerontology, 16, 75-80.

Baider, L., Peretz, T., \& Kaplan De-Nour, A. (1992). Effect of the Holocaust on coping with cancer. Social Science and Medicine, 34, 11-15.

Baider, L., Peretz, T., \& Kaplan De-Nour, A. (1993). Holocaust cancer patients: A comparative study. Psychiatry, 56, 349-355. 
Benbow, S.M., \& Haddad, P.M. (1993). Sexual abuse of the elderly mentally ill. Postgraduate Medical Journal, 69, 803-807.

Brower, H.T. (1981). Social organization and nurses' attitudes toward older persons. Journal of Gerontological Nursing, 7, 293-298.

Burgess, A.W., Dowdell, E.B., \& Prentky, R.A. (2000). Sexual abuse of nursing home residents. Journal of Psychosocial Nursing, 38, 10-18.

Campbell, M.E. (1971). Study of the attitudes of nursing personnel toward the geriatric patient. American Journal of Nursing, 20, 147-151.

Coffey, P., Leitenberg, H., Henning, K., Turner, T., \& Bennett, R. (1996). Mediators of the long-term impact of child sexual abuse: Perceived stigma, betrayal, powerlessness, and self-blame. Child Abuse and Neglect, 20, 447-455.

Comijs, H.C., Pot, A.M., Smit, J.H., Bouter, L.M., \& Jonker, C. (1998). Elder abuse in the community: Prevalence and consequences. Journal of the American Geriatrics Society, 46, 885-888.

Cooper, S.M. (2002). Clinicians' diagnostic practices with senior survivors of childhood trauma. Unpublished master's thesis, Carleton University, Ottawa, Ontario, Canada.

Cooper, S.M., \& Kristiansen, C.M. (2004). Clinicians' diagnostic practices with senior survivors of childhood trauma. Paper presented at the Ontario Elder Abuse Conference, Toronto, Ontario.

Coyne, A.C., Reichman, W.E., \& Berbig, L.J. (1993). The relationship between dementia and elder abuse. American Journal of Psychiatry, 150, 643-646.

Danieli, Y. (1997). As survivors age: An overview. Geriatric Psychiatry, 30, 9-26. 
David, P., \& Pelly, S. (2003). Caring for aging Holocaust survivors: A practice manual. Toronto, ON: Baycrest Centre for Geriatric Care.

Dey, I. (1999). Grounding grounded theory: Guidelines for qualitative inquiry. San Diego: Academic Press.

Ebersole, P., Hess, P., \& Luggan, A.S. (2004). Toward healthy aging: Human needs and nursing response $\left(6^{\text {th }}\right.$ ed.). St. Louis, MO: Mosby.

Engdahl, B., Dikel, T.N., Eberly, R., \& Blank, A. (1997). Posttraumatic stress disorder in a community group of former prisoners of war: A normative response to severe trauma. American Journal of Psychiatry, 154, 1576-1581.

Falk, B., Hersen, M., \& Van Hasselt, V.B. (1994). Assessment of post-traumatic stress disorder in older adults: A critical review. Clinical Psychology Review, 14, 383415.

Finkelhor, D., \& Browne, A. (1985). The traumatic impact of child sexual abuse: A conceptualization. American Journal of Orthopsychiatry, 55, 530-541.

Friedan, B. (1993). The fountain of age. New York: Simon \& Schuster.

Fromuth, M., \& Burkhart, B. (1992). Recovery or recapitulation? An analysis of the impact of psychiatric hospitalization on the child abuse survivor. Women and Therapy, 12, 81-95.

Gagnon, M., \& Hersen, M. (2000). Unresolved childhood sexual abuse and older adults: Late-life vulnerabilities. Journal of Clinical Geropsychology, 6, 187-198.

Gentlewarrior, S. (1997). Symptoms of trauma in middle-aged and older female survivors of child sexual abuse: An ecological examination of risk and protective factors. Unpublished doctoral dissertation, Simmons College School of Social Work. 
Grainger, K. (1993). "That's a lovely bath dear:" Reality construction in the discourse of elderly care. Journal of Aging Studies, 7, 247-262.

Granatstein, J.L. (1969). Conscription in the second world war 1939-1945: A study in political management. Toronto: The Ryerson Press.

Grossman, A.B., Levin, B.E., Katzen, H.L., \& Lechner, S. (2004). PTSD symptoms and onset of neurologic disease in elderly trauma survivors. Journal of Clinical and Experimental Neuropsychology, 26, 698-705.

Haight, B.K., Christ, M.A., \& Dias, J.K. (1994). Does nursing education promote ageism? Journal of Advanced Nursing, 20, 382-390.

Hausdorff, J.M., Levy, B.R., \& Wei, J.Y. (1999). The power of ageism on physical function of older persons: Reversibility of age-related gait changes. Journal of the American Geriatrics Society, 47, 1346-1349.

Hazzard, A. (1993). Trauma-related beliefs as mediators of sexual abuse impact in adult women survivors: A pilot study. Journal of Child Sexual Abuse, 2, 55-69.

Hefner, R. L. (2001). Exploring the perceptions of nursing personnel towards the elderly. Unpublished doctoral dissertation, Chicago School of Professional Psychology.

Heney, J., \& Kristiansen, C.M. (1997). An analysis of the impact of prison on women survivors of childhood sexual abuse. Women and Therapy, 20, 29-44.

Heney, J., \& Kristiansen, C.M. (2003). Working with women in conflict with the law: A trainer's manual. Toronto, ON: Ontario Ministry of Security and Public Safety.

Herman, J.L. (1992). Trauma and recovery. New York: Basic Books.

Higgins, A.B. (1999). The dialectic of trauma: Trauma symptoms and resiliency in older women. Unpublished doctoral dissertation, University of Nevada, Reno. 
Hocking, F.A. (1970). Psychiatric aspects of extreme environmental stress. Diseases of the Nervous System, 31, 542-545.

Ingham, R., \& Fielding, P. (1985). A review of the nursing literature on attitudes toward old people. International Journal of Nursing Studies, 22, 171-181.

Johnston, D. (2000). A series of cases of dementia presenting with PTSD symptoms in World War II combat veterans. Journal of the American Geriatrics Society, 48, 70-72.

Joffe, C., Brodaty, H., Luscombe, G., \& Ehrlich, F. (2003). The Sydney Holocaust study: Posttraumatic stress disorder and other psychosocial morbidity in an aged community sample. Journal of Traumatic Stress, 16, 39-47.

Jongedijk, R.A., Carlier, I.V., Schreuder, B.J., \& Gersons, B.P. (1996). Complex posttraumatic stress disorder: An exploratory investigation of PTSD and DESNOS among Dutch war veterans. Journal of Traumatic Stress, 9, 577-586.

Kaup, B.A., Ruskin, P.E., \& Nyman, G. (1994). Significant life events and PTSD in elderly World War II veterans. American Journal of Geriatric Psychiatry, 2, 239243.

Kemper, P., \& Murtaugh, C.M. (1991). Lifetime use of nursing home care. New England Journal of Medicine, 324, 595-600.

Kite, M. E., Stockdale, G. D., Whitley, B. E., \& Johnson, B. T. (2005). Attitudes toward younger and older adults: An updated meta-analytic review. Journal of Social Issues, 61, 241-266. 
Kristiansen, C.M. (2003, October). The long-term effects of childhood and adult abuse on senior women. Keynote address to the Annual Convention of the Ontario Association of Social Workers, Ottawa, Ontario.

Kristiansen, C.M. (2004, April). The neurobiological effects of trauma on mind and body. Invited keynote address to $10^{\text {th }}$ Annual Conference of the Ontario Network of Sexual Assault/Domestic Violence Treatment Centres, Hamilton, Ontario.

Kristiansen, C.M. \& Hay, E.L. (2000, July). The impact of aging on women survivors of childhood and adult assault. Paper presented to the Annual Convention of the Canadian Psychological Association, Ottawa, Ontario.

Kuch, K., \& Cox, B.J. (1992). Symptoms of PTSD in 124 survivors of the Holocaust. American Journal of Psychiatry, 149, 337-340.

Langer, E. J., \& Rodin, J (1976). The effects of choice and enhanced personal responsibility for the aged: A field experiment in an institutionalized setting. Journal of Personality and Social Psychology, 34, 191-198.

Langer, E. J. (1983). The psychology of control. Beverly Hills, CA: Sage.

Lee, J., \& Carr, M.B. (1993). The empowerment of women residents in the nursing home. Women \& Therapy, 14,187-203.

Leskela, J., Dierperink, M., \& Thuras, P. (2002). Shame and posttraumatic stress disorder. Journal of Traumatic Stress, 15, 223-226.

McInnis-Dittrich, K. (1996). Adapting the life-review interview therapy for elderly female survivors of childhood sexual abuse. Families in Society, 77, 166-173. 
Meshal, D.S., \& McGlynn, R.P. (2004). Intergenerational contact, attitudes, and stereotypes of adolescents and older people. Educational Gerontology, 30, 457479.

Miller, C.A. (2004). Nursing for wellness in older adults: Theory and practice ( $^{\text {th }} \mathrm{ed}$.). Philadelphia, PA: Lippincott Williams \& Wilkins.

Mittal, D., Torres, R., Abashidze, A., \& Jimerson, N. (2001). Worsening of posttraumatic stress disorder symptoms with cognitive decline: Case series. Journal of Geriatric Psychiatry and Neurology, 14, 17-20.

Norris, F.H. (1992). Epidemiology of trauma: Frequency and impact of different potentially traumatic events on different demographic groups. Journal of Consulting and Clinical Psychology, 60, 409-418.

Novak, M., \& Chappell, N. L. (1994). Nursing assistant burnout and the cognitively impaired elderly. International Journal on Aging and Human Development, 39, 105-120.

Nussbaum, J.F. (1993). The communicative impact of institutionalization for the elderly: The admissions process. Journal of Aging Studies, 7, 237-246.

O'Connor, B.P., \& St. Pierre, E. S. (2004). Older persons' perceptions of the frequency and meaning of elderspeak from family, friends, and service workers. International Journal of Aging and Human Development, 58, 197-221.

Op den Velde, W., Falgar, P.J., Hovens, J.E., de Groen, J., Lasschuit, L., Van Duijin, H., \& Schouten, E.G. (1993). Posttraumatic stress disorder in Dutch resistance veterans from World War II. In J.P. Wilson, \& B. Raphael (Eds.), International handbook of traumatic stress syndromes (pp. 219-230). New York: Plenum Press. 
Palmer, A.M.C. (2005). Caregivers' experiences with senior trauma survivors with dementia. Unpublished Honours BA thesis, Carleton University, Ottawa, Ontario, Canada.

Palmore, E. (2001). The ageism survey: First findings. The Gerontologist, 41, 572-575.

Parrent, J. (2001). A caregiver's guide through each stage of Alzheimer's. Indianapolis: Alpha Books.

Pary, R., Turns, D.M., \& Tobias, C.R. (1986). A case of delayed recognition of posttraumatic stress disorder. American Journal of Psychiatry, 143, 941.

Pearlman, S.F. (1993). Late mid-life astonishment: Disruptions to identity and selfesteem. Women and Therapy, 14, 1-12.

Pillemer, K., \& Finkelhor, D. (1988). The prevalence of elder abuse: A random sample survey. The Gerontological society of America, 28, 51-57.

Pillemer, K., \& Moore, D.W. (1989). Abuse of patients in nursing homes: Findings from a staff survey. The Gerontologist, 29, 314-320.

Podnieks, E., Pillemer, K., Nicholson, P., Shillington, T., \& Frizzell, A. (1990). National survey on abuse of the elderly in Canada. Toronto, ON: Ryerson Polytechnical Institute.

Port, C.L. (1998). Posttraumatic stress and aging in older survivors of remote trauma. Unpublished doctoral dissertation, University of Minnesota.

Rockwood, K., \& MacKnight, C. (2001). Understanding dementia: A primer of diagnosis and management. Halifax, NS: Pottersfield Press.

Roth, S., Newman, E., Pelcovitz, D., van der Kolk, B.A, \& Mandel, F.S. (1997). Complex PTSD in victims exposed to sexual and physical abuse: Results for the 
DSM-IV field trial for posttraumatic stress disorder. Journal of Traumatic Stress, $10,539-555$.

Ryan, E.B., Bourhis, R.Y., \& Knops, U. (1991). Evaluative perceptions of patronizing speech addressed to elders. Psychology and Aging, 6, 442-450.

Ryan, E.B., Meredith, S.D., MacLean, M.J., \& Orange, J.B. (1995), Changing the way we talk with elders: Promoting health using the communication enhancement model. International Journal of Aging and Human Development, 41, 89-107.

Schmotkin, D., Blumstein, T., \& Modan, B. (2003). Tracing long-term effects of early trauma: A broad-scope view of Holocaust survivors in late life. Journal of Consulting and Clinical Psychology, 71, 223-234.

Seale, C. (1999). The quality of qualitative research. Thousand Oaks, CA: Sage.

Shinoda-Tagawa, T., Leonard, R., Pontikas, J., McDonough, J.E., Allen, D., \& Dreyer, P.I. (2004). Resident-to-resident violent incidents in nursing homes. Journal of the American Medical Association, 291, 591-598.

Snape, J. (1986). Nurses' attitudes to care of the elderly. Journal of Advanced Nursing, 11, 569-572.

Stanley, M., Blair, K.A., \& Beare, P.G. (2005). Gerontological nursing: Promoting successful aging with older adults $\left(3^{\text {rd }}\right.$ ed.). Philadelphia, PA: F.A. Davis Company.

Statistics Canada (2002a, July 16). Age and sex, percentage change (1996-2001) for both sexes, for Canada, provinces and territories-100\% data. Retrieved October 27, 2003, from http://www12.statcan.ca/english/census01/products/highlight/Age Sex/Page.cfm? 
Statistics Canada (2002b, July 16). Age and sex. Retrieved October 27, 2003, from http://www12.statcan.ca/english/census01/release/age_sex.cfm?Lang=E\&Geo=P $\mathrm{R} \&$ View $=1 \&$ Code $=0 \&$ Table $=3 \mathrm{a} \&$ StartRe $=1 \&$ Sort $=2 \& \mathrm{~B} 1=$ Change $\& \mathrm{~B} 2=$ Both Stones, M. (1997). Alzheimer's disease and aggression: A guide for caregivers. North York: Captus Press.

Summit, R.C. (1983). The child sexual abuse accommodation syndrome. Child Abuse and Neglect, 7, 177-193.

Sutker, P., \& Allain, A. (1996). Assessment of PTSD and other mental disorders in World War II and Korean conflict POW survivors and combat veterans. Psychological Assessment, 8, 18-25.

Tuckman, J., \& Lorge, I. (1953). Attitudes toward old people. Journal of Social Psychology, 37, 249-260.

van Achterberg, M.E., Rohrbaugh, R.M., \& Southwick, S.M. (2001). Emergence of PTSD in trauma survivors with dementia. Journal of Clinical Psychiatry, 62, 206207.

van der Kolk, B.A. (1996). The complexity of adaptation to trauma: Self-regulation., stimulus discrimination, and characterological development. In B.A. van der Kolk, A.C. McFarlane \& L. Weisaeth (Eds.), Traumatic stress: The effects of overwhelming experience on mind, body, and society (pp. 182-213). New York: Guilford Press.

van der Kolk, B.A., Pelcovitz, D., Roth, S., Mandel, F.S., McFarlane, A., \& Herman, J.L. (1996). Dissociation, somatization, and affect dysregulation: The complexity of adaptation to trauma. American Journal of Psychiatry, 153 (Suppl.), 83-92. 
Weintraub, D., \& Ruskin, P.E. (1999). Posttraumatic stress disorder in the elderly: A review. Harvard Review of Psychiatry, 7, 144-152.

Wickett, J., \& Kristiansen, C.M. (2005). Seniors' life experiences, coping and wellbeing. Ongoing research, Carleton University, Ottawa, Ontario, Canada.

Wood, L.A., \& Kroger, R.O. (1993). Forms of address, discourse and aging. Journal of Aging Studies, 7, 263-277.

Yehuda, R., Kahana, B., Southwick, S., \& Giller, E.L. (1994). Depressive features in Holocaust survivors with post-traumatic stress disorder. Journal of Traumatic Stress, 7, 699-704. 
Appendix A

Figures and Tables 
Figure 1

Baycrest Model of Caring for Aging Holocaust Survivors

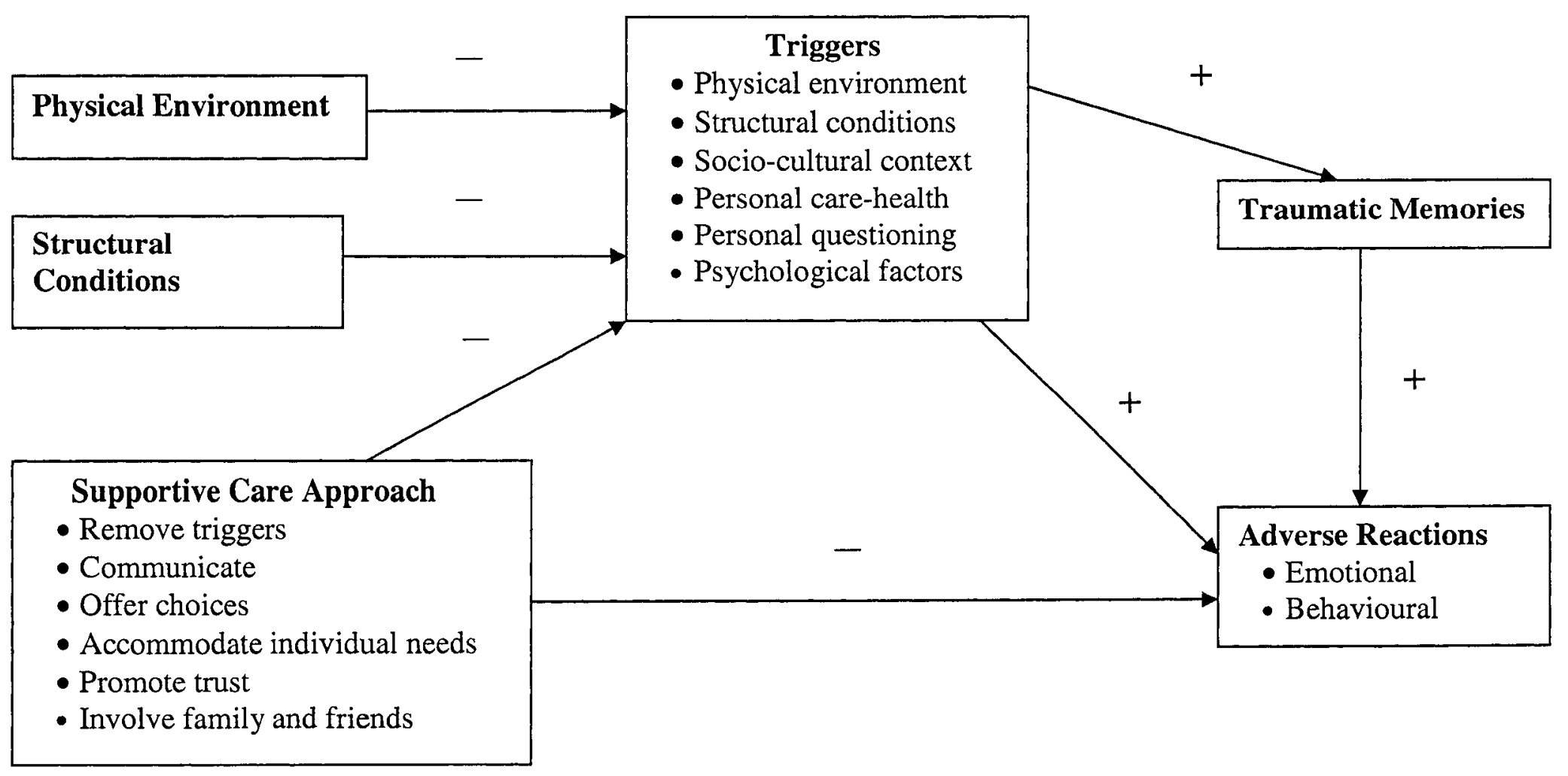


Figure 2

Factors Affecting the Well-Being of Senior Trauma Survivors in Residential Care

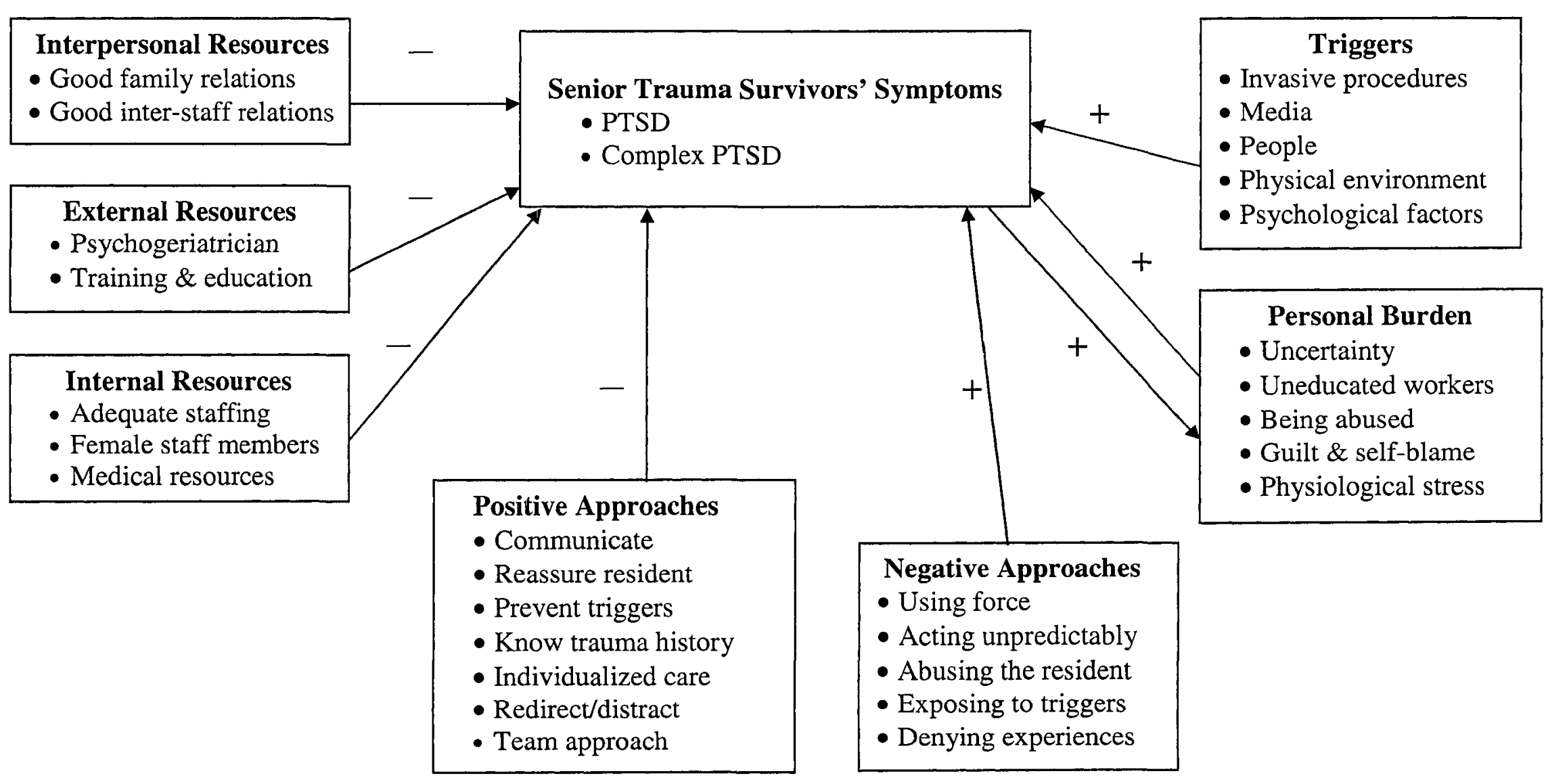


Table 1

\section{Characteristics of the Six Long-Term Care Facilities}

\begin{tabular}{|c|c|c|c|c|c|c|c|c|}
\hline \multirow[b]{2}{*}{ Characteristic } & \multicolumn{7}{|c|}{ Facility } & \multirow[b]{2}{*}{$\underline{S D}$} \\
\hline & $\underline{1}$ & $\underline{2}$ & $\underline{3}$ & 4 & $\underline{5}$ & $\underline{6}$ & $\underline{M}$ & \\
\hline Number of residents & 240 & 240 & 219 & 193 & 192 & 100 & 197.3 & 52.21 \\
\hline$\%$ female residents & 72 & 80 & 73 & 70 & 70 & 76 & 73.5 & 3.89 \\
\hline Residents' ethnicity & White & Mixed & White & Mixed & Immigrants & European & - & - \\
\hline \multicolumn{9}{|l|}{ Employee status (\%): } \\
\hline Full-time & 60 & - & 33 & Some & 40 & 41 & 43.50 & 11.56 \\
\hline Part-time & 40 & - & 51 & Many & 55 & 28 & 43.50 & 12.12 \\
\hline Casual & 0 & - & 16 & Lots & 5 & 31 & 17.33 & 13.05 \\
\hline
\end{tabular}


Table 1 Cont'd

Characteristics of the Six Long-Term Care Facilities

\begin{tabular}{|c|c|c|c|c|c|c|c|c|}
\hline \multirow[b]{2}{*}{ Characteristic } & \multicolumn{7}{|c|}{ Facility } & \multirow[b]{2}{*}{$\underline{S D}$} \\
\hline & 1 & $\underline{2}$ & $\underline{3}$ & $\underline{4}$ & $\underline{5}$ & $\underline{6}$ & $\underline{M}$ & \\
\hline \multicolumn{9}{|l|}{ Position (\%): } \\
\hline Registered nurse & 26 & 20 & 15 & 15 & 30 & 76 & 19.33 & 7.53 \\
\hline Registered/Licensed practical nurse & 18 & 20 & 33 & 35 & 30 & 10 & 24.33 & 9.85 \\
\hline Personal support worker & 120 & 110 & 165 & 140 & 120 & 10 & 119.83 & 35.97 \\
\hline Volunteer & 72 & 500 & 200 & 100 & 192 & 0 & 177.33 & 175.14 \\
\hline Restorative care worker & 1 & 3 & 2 & 4 & 15 & 1 & 4.33 & 5.35 \\
\hline Social worker & 1 & 1 & 0 & 1 & 0 & 2 & 0.83 & 0.75 \\
\hline Occupational/physiotherapist & 6 & 0 & 3 & 2 & As needed & 1 & 2.40 & 2.30 \\
\hline Recreational therapist & 11 & 7 & 5 & 3 & 5 & 2 & 5.50 & 3.21 \\
\hline Support services & 45 & 42 & 0 & 37 & 65 & 32 & 36.83 & 21.29 \\
\hline
\end{tabular}


Table 2

Trauma-Related Characteristics of the Six Long-Term Care Facilities

\begin{tabular}{|c|c|c|c|c|c|c|c|}
\hline \multirow[b]{2}{*}{ Characteristic } & \multicolumn{7}{|c|}{ Facility } \\
\hline & $\underline{1}$ & $\underline{2}$ & $\underline{3}$ & $\underline{4}$ & $\underline{5}$ & $\underline{6}$ & $\%$ yes \\
\hline Inquire about history of trauma & Never & Never & Never & Sometimes & Never & Always & 33.33 \\
\hline Treatment for psychological problems & Yes & Yes & Yes & Yes & Yes & Yes & 100.00 \\
\hline Treatment for trauma survivors & No & No & No & Yes & No & Yes & 33.33 \\
\hline Training regarding earlier trauma & No & No & No & No & Yes & Yes & 33.33 \\
\hline
\end{tabular}


Table 3

Results of Item Analyses and Descriptive Statistics for Scale Scores

\begin{tabular}{|c|c|c|c|c|c|}
\hline Scale & $N$ items & $\begin{array}{l}M \text { inter- } \\
\text { item } r\end{array}$ & $\alpha$ & $M$ & $S D$ \\
\hline Training & 3 & .66 & .84 & 1.35 & 1.04 \\
\hline Familiarity with residents & 3 & .59 & .78 & 0.00 & .85 \\
\hline \multicolumn{6}{|l|}{ Traumagenic dynamics } \\
\hline Powerlessness & 3 & .66 & .85 & 1.84 & 1.07 \\
\hline Betrayal & 3 & .51 & .76 & 1.47 & 0.81 \\
\hline Attitudes & 9 & .39 & .86 & 4.31 & 1.04 \\
\hline Verbal abuse & 3 & .43 & .68 & 1.14 & 0.82 \\
\hline Physical abuse & 2 & .82 & .90 & 0.40 & 0.79 \\
\hline \multicolumn{6}{|l|}{ PTSD symptoms } \\
\hline Intrusive experiences & 3 & .61 & .82 & 1.48 & 0.83 \\
\hline Avoidance behaviour & 3 & .45 & .69 & 1.44 & 0.80 \\
\hline Hyperarousal & 4 & .74 & .92 & 1.82 & 1.03 \\
\hline
\end{tabular}

Note. The potential range of each scale was 0 to 4 , except for the measure of Attitudes that could potentially range from 1 to 7 and the measure of Familiarity that was based on $\mathrm{Z}$ scores. 
Table 4

Descriptive Statistics for Measures of Participants' Gerontology and Trauma-Related Training

\begin{tabular}{|c|c|c|c|c|c|c|c|c|c|c|c|c|}
\hline \multirow[b]{2}{*}{ Type of training } & \multicolumn{2}{|c|}{ None } & \multicolumn{2}{|c|}{$\underline{\text { A little }}$} & \multicolumn{2}{|c|}{$\begin{array}{l}\text { Moderate } \\
\text { amount }\end{array}$} & \multicolumn{2}{|c|}{$\begin{array}{c}\text { A Good } \\
\text { deal }\end{array}$} & \multicolumn{2}{|c|}{$\begin{array}{c}\text { A great } \\
\text { deal }\end{array}$} & \multirow[b]{2}{*}{$\underline{M}$} & \multirow[b]{2}{*}{$\underline{S D}$} \\
\hline & $\underline{n}$ & $\underline{\%}$ & $\underline{n}$ & $\underline{\%}$ & $\underline{n}$ & $\underline{\%}$ & $\underline{n}$ & $\underline{\%}$ & $\underline{n}$ & $\underline{q}$ & & \\
\hline Overall training & & & & & & & & & & & 1.35 & 1.04 \\
\hline Specialized gerontology & 12 & 19.7 & 17 & 27.9 & 8 & 13.1 & 16 & 26.2 & 8 & 13.1 & 1.85 & 1.36 \\
\hline Effects of trauma on people & 17 & 27.4 & 23 & 37.1 & 11 & 17.7 & 8 & 12.9 & 3 & 4.8 & 1.31 & 1.15 \\
\hline Effects of trauma on seniors & 25 & 40.3 & 23 & 37.1 & 8 & 12.9 & 5 & 8.1 & 1 & 1.6 & 0.94 & 1.01 \\
\hline
\end{tabular}


Table 5

Descriptive Statistics for Measures of Participants' Familiarity with Residents

\begin{tabular}{|c|c|c|c|c|c|c|c|c|c|c|c|c|}
\hline \multirow[b]{2}{*}{ Familiarity item } & \multicolumn{2}{|c|}{$\begin{array}{c}\text { Never/ } \\
\text { Not at all } \\
\end{array}$} & \multicolumn{2}{|c|}{$\begin{array}{l}\text { Rarely/ } \\
\text { A little }\end{array}$} & \multicolumn{2}{|c|}{$\begin{array}{l}\text { Sometimes/ } \\
\text { Fairly well }\end{array}$} & \multicolumn{2}{|c|}{$\begin{array}{l}\text { Usually/ } \\
\text { Very well }\end{array}$} & \multicolumn{2}{|c|}{ Always } & \multirow[b]{2}{*}{$\underline{M}$} & \multirow[b]{2}{*}{$\underline{S D}$} \\
\hline & $\underline{n}$ & $\underline{\%}$ & $\underline{n}$ & $\underline{\%}$ & $\underline{n}$ & $\underline{\%}$ & $\underline{n}$ & $\underline{\%}$ & $\underline{n}$ & $\underline{\%}$ & & \\
\hline Review residents' life history & 6 & 9.7 & 9 & 14.5 & 16 & 25.8 & 18 & 29.0 & 13 & 21.0 & 2.37 & 1.24 \\
\hline Get to know residents & 12 & 19.4 & 2 & 3.2 & 24 & 38.7 & 24 & 38.7 & 0 & - & 2.18 & 0.75 \\
\hline Work with same residents & 3 & 4.8 & 13 & 21.0 & 8 & 12.9 & 17 & 27.4 & 21 & 33.9 & 2.65 & 1.28 \\
\hline
\end{tabular}

Note. Review residents' life history and Work with same residents scores could range from 0 (Not at all) to 5 (Always) while Get to know residents scores could range from 0 (Not at all) to 4 (Very well). 
Table 6

Frequency Participants Witnessed Potentially Traumagenic Behaviours

\begin{tabular}{|c|c|c|c|c|c|c|c|c|c|c|c|c|}
\hline \multirow[b]{2}{*}{ Traumagenic behaviour } & \multicolumn{2}{|c|}{ Never } & \multicolumn{2}{|c|}{$\begin{array}{c}\text { Once } \\
\text { or twice }\end{array}$} & \multicolumn{2}{|c|}{$\begin{array}{l}\text { A few } \\
\underline{\text { times }}\end{array}$} & \multicolumn{2}{|c|}{$\begin{array}{l}\text { Many } \\
\text { times } \\
\end{array}$} & \multicolumn{2}{|c|}{$\begin{array}{l}\text { Very many } \\
\text { times }\end{array}$} & \multirow[b]{2}{*}{$\underline{M}$} & \multirow[b]{2}{*}{$\underline{S D}$} \\
\hline & $\underline{n}$ & $\underline{\%}$ & $\underline{n}$ & $\underline{\%}$ & $\underline{n}$ & $\underline{\%}$ & $\underline{n}$ & $\underline{\text { q }}$ & $\underline{n}$ & $\underline{\%}$ & & \\
\hline Powerlessness total: & & & & & & & & & & & 1.84 & 1.07 \\
\hline Enter resident's room & 10 & 16.7 & 8 & 13.3 & 12 & 20.0 & 20 & 33.3 & 10 & 16.1 & 2.20 & 1.34 \\
\hline Make decision for resident & 10 & 16.7 & 11 & 18.3 & 20 & 33.3 & 15 & 25.0 & 4 & 6.5 & 1.87 & 1.17 \\
\hline 'Order' a resident & 13 & 21.7 & 22 & 36.7 & 13 & 21.7 & 9 & 15.0 & 3 & 5.0 & 1.45 & 1.14 \\
\hline Betrayal total: & & & & & & & & & & & 1.47 & 0.81 \\
\hline Promise and no time & 5 & 8.2 & 15 & 24.6 & 20 & 32.8 & 18 & 29.5 & 3 & 4.9 & 1.98 & 1.04 \\
\hline Promise and forget & 10 & 16.4 & 15 & 24.6 & 25 & 41.0 & 9 & 14.8 & 2 & 3.3 & 1.64 & 1.03 \\
\hline Break resident's trust & 30 & 49.2 & 15 & 24.6 & 15 & 24.6 & 1 & 1.6 & 0 & 0 & 0.79 & 0.88 \\
\hline Verbal abuse total: & & & & & & & & & & & 1.14 & 0.82 \\
\hline Talk to as if a child & 11 & 17.7 & 18 & 29.0 & 20 & 32.3 & 10 & 16.1 & 3 & 4.8 & 1.61 & 1.11 \\
\hline Insult, tease, or swear & 29 & 46.8 & 16 & 25.8 & 11 & 17.7 & 4 & 6.5 & 2 & 3.2 & 0.94 & 1.10 \\
\hline Yell in anger & 27 & 43.5 & 19 & 30.6 & 13 & 21.0 & 3 & 4.8 & 0 & 0 & 0.87 & 0.91 \\
\hline Physical abuse total: & & & & & & & & & & & 0.40 & 0.79 \\
\hline Grab, push or shove & 43 & 69.4 & 13 & 21.0 & 4 & 6.5 & 1 & 1.6 & 1 & 1.6 & 0.45 & 0.82 \\
\hline Slap, hit or kick & 50 & 80.6 & 5 & 8.1 & 5 & 8.1 & 1 & 1.6 & 1 & 1.6 & 0.35 & 0.83 \\
\hline Touch resident in sexual way & 57 & 91.9 & 4 & 6.5 & 0 & 0 & 1 & 1.6 & 0 & 0 & 0.11 & 0.45 \\
\hline Ignore needs or fail to do things & 13 & 21.0 & 23 & 37.1 & 18 & 29.0 & 7 & 11.3 & 1 & 1.6 & 1.35 & 0.99 \\
\hline
\end{tabular}


Table 7

Number of Trauma Survivors Participants Worked With by Type of Trauma

\begin{tabular}{|c|c|c|c|c|c|c|c|c|c|c|}
\hline \multirow[b]{2}{*}{ Type of trauma } & \multicolumn{2}{|c|}{ None } & \multicolumn{2}{|c|}{$\underline{A f e w}$} & \multicolumn{2}{|c|}{$\underline{\text { Some }}$} & \multicolumn{2}{|c|}{$\underline{\text { Many }}$} & \multirow[b]{2}{*}{$\underline{M}$} & \multirow[b]{2}{*}{$\underline{S D}$} \\
\hline & $\underline{n}$ & $\underline{\%}$ & $\underline{n}$ & $\underline{\%}$ & $\underline{n}$ & $\underline{\%}$ & $\underline{n}$ & $\underline{\%}$ & & \\
\hline Combat & 3 & 6.3 & 18 & 37.5 & 19 & 39.6 & 8 & 16.7 & 1.67 & 0.83 \\
\hline Adult physical assault & 4 & 10.3 & 18 & 46.2 & 14 & 35.9 & 3 & 7.7 & 1.41 & 0.78 \\
\hline Childhood physical abuse & 6 & 16.2 & 15 & 40.5 & 12 & 32.4 & 4 & 10.8 & 1.38 & 0.89 \\
\hline Childhood sexual abuse & 6 & 15.0 & 19 & 47.5 & 12 & 30.0 & 3 & 7.5 & 1.30 & 0.82 \\
\hline Concentration camp survivor & 6 & 12.8 & 28 & 59.6 & 9 & 19.1 & 4 & 8.5 & 1.23 & 0.79 \\
\hline Prisoner of War (POW) & 9 & 22.5 & 22 & 55.0 & 9 & 22.5 & 0 & 0 & 1.00 & 0.68 \\
\hline Adult rape/sexual assault & 15 & 38.5 & 15 & 38.5 & 7 & 17.9 & 2 & 5.1 & 0.90 & 0.88 \\
\hline Other traumas ${ }^{\mathrm{a}}$ & 6 & 37.5 & 8 & 50.0 & 2 & 12.5 & 0 & 0 & 0.75 & 0.68 \\
\hline
\end{tabular}

Note. Responses could range from None (0) to Many (3).

${ }^{a}$ Other traumas included homelessness, being an abuser, stabbing, Holocaust survivor but not in a camp, and Soviet Bloc. 
Table 8

Descriptive Statistics for Participants' Ratings of the Number of Senior Trauma Survivors Having PTSD Symptoms

\begin{tabular}{|c|c|c|c|c|c|c|c|c|c|c|c|c|}
\hline \multirow[b]{2}{*}{ PTSD symptom } & \multicolumn{2}{|c|}{ None } & \multicolumn{2}{|c|}{ A few } & \multicolumn{2}{|c|}{ About half } & \multicolumn{2}{|c|}{$\underline{\text { Mlost }}$} & \multicolumn{2}{|c|}{$\underline{\text { All }}$} & \multirow[b]{2}{*}{$\underline{M}$} & \multirow[b]{2}{*}{$\underline{S D}$} \\
\hline & $\underline{n}$ & $\underline{\%}$ & $\underline{n}$ & $\underline{\%}$ & $\underline{n}$ & $\underline{\%}$ & $\underline{n}$ & $\underline{\%}$ & $\underline{n}$ & $\underline{\%}$ & & \\
\hline Intrusive experiences total & & & & & & & & & & & 1.48 & 0.83 \\
\hline Upset in similar situations & 3 & 6.8 & 17 & 38.6 & 8 & 18.2 & 13 & 29.5 & 3 & 6.8 & 1.91 & 1.12 \\
\hline Upsetting memories/dreams & 4 & 8.9 & 25 & 55.6 & 10 & 22.2 & 5 & 11.1 & 1 & 2.2 & 1.42 & 0.89 \\
\hline Reliving the trauma & 9 & 20.0 & 26 & 57.8 & 5 & 11.1 & 5 & 11.1 & 0 & 0.0 & 1.13 & 0.87 \\
\hline Avoidance behaviours total & & & & & & & & & & & 1.44 & 0.80 \\
\hline Avoid talking about trauma & 6 & 14.0 & 13 & 30.2 & 7 & 16.3 & 16 & 37.2 & 1 & 2.3 & 1.84 & 1.15 \\
\hline Seemed detached & 7 & 15.6 & 22 & 48.9 & 8 & 17.8 & 7 & 15.6 & 1 & 2.2 & 1.40 & 1.01 \\
\hline Seemed numb & 7 & 15.9 & 29 & 65.9 & 5 & 11.4 & 2 & 4.5 & 1 & 2.3 & 1.11 & 0.81 \\
\hline Hyperarousal total & & & & & & & & & & & 1.82 & 1.03 \\
\hline Seemed nervous & 3 & 6.5 & 17 & 37.0 & 9 & 19.6 & 16 & 34.8 & 1 & 2.2 & 1.89 & 1.04 \\
\hline Angry outbursts & 5 & 10.9 & 18 & 39.1 & 7 & 15.2 & 12 & 26.1 & 4 & 8.7 & 1.83 & 1.20 \\
\hline Trouble sleeping/concentrating & 5 & 11.4 & 15 & 34.1 & 12 & 27.3 & 8 & 18.2 & 4 & 9.1 & 1.80 & 1.15 \\
\hline Seemed moody/irritable & 5 & 11.1 & 17 & 37.8 & 9 & 20.0 & 10 & 22.2 & 4 & 8.9 & 1.80 & 1.18 \\
\hline
\end{tabular}

Note. Responses could range from None (0) to All (4). 
Table 9

Descriptive Statistics for Participants' Ratings of Other Indicators of Senior Trauma Survivors' Well-Being

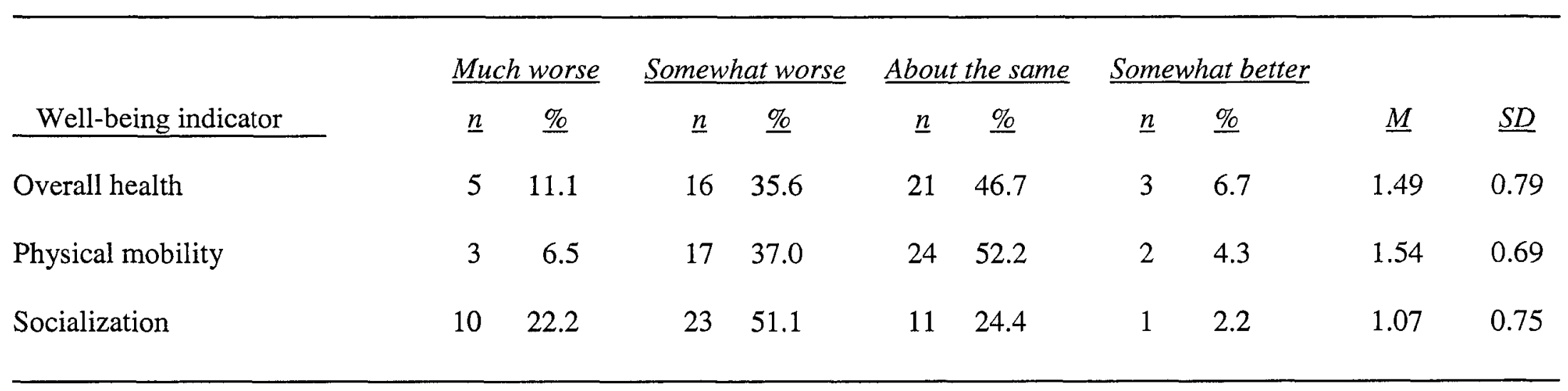

Note. Responses could range from Much worse (0) to Much better (4). None of the participants rated senior trauma survivors as Much Better. 
Table 10

Correlations of Participants' Training, Familiarity and Attitude Scores with Frequency They

Witnessed Traumagenic Dynamics and Number of Trauma Survivors They Worked With

\begin{tabular}{|c|c|c|c|c|c|c|}
\hline \multicolumn{7}{|c|}{ Training } \\
\hline Variable & $\underline{\text { Gerontology }}$ & $\underline{\text { Trauma }}$ & $\underline{\text { Senior trauma }}$ & Total & Familiarity & $\underline{\text { Attitudes }}$ \\
\hline Familiarity & $.35^{* *}$ & $.47 * * *$ & $.39 * *$ & $.47 * * *$ & - & $-.24^{\dagger}$ \\
\hline Attitudes & -.16 & -.21 & $-.28^{*}$ & $-.24^{\dagger}$ & -.24 & - \\
\hline \multicolumn{7}{|l|}{ Traumagenic dynamics: } \\
\hline Powerlessness & .12 & .17 & .08 & .15 & .22 & $-.40 * *$ \\
\hline Betrayal & .08 & $.25^{\dagger}$ & .18 & .20 & $.28^{*}$ & $-.37 * *$ \\
\hline Verbal abuse & .03 & .10 & -.13 & .03 & .15 & $-.29 *$ \\
\hline Physical abuse & $.24^{\dagger}$ & $.38 * *$ & $.28 *$ & $.34 * *$ & $.22^{\dagger}$ & $-.22^{\dagger}$ \\
\hline Touch sexually & $.24^{\dagger}$ & $.28^{*}$ & $.31^{*}$ & $.31^{*}$ & $.28^{*}$ & $-.25^{\dagger}$ \\
\hline Neglect & .05 & -.12 & -.16 & -.01 & $-.23^{\dagger}$ & -.21 \\
\hline Number trauma survivors & .08 & .16 & .14 & .14 & .10 & -.20 \\
\hline
\end{tabular}

${ }^{\dagger} p<.10 .{ }^{*} p<.05 .{ }^{*} p<.01 .{ }^{* * *} p<.001$. Two-tailed.

Note. Ns range from 59 to 62 . 
Table 11

Correlations of Participants' Training, Familiarity and Attitude Scores with Measures of Senior Trauma Survivors' Well-Being

\begin{tabular}{|c|c|c|c|c|c|c|}
\hline \multicolumn{7}{|c|}{ Training } \\
\hline Variable & Gerontology & $\underline{\text { Trauma }}$ & $\underline{\text { Senior trauma }}$ & Total & Familiarity & Attitudes \\
\hline Talk about trauma & .21 & .12 & $.26^{\dagger}$ & .22 & $.31^{*}$ & -.21 \\
\hline Think about trauma & .05 & -.02 & .14 & .06 & -.01 & -.21 \\
\hline Feelings when think & -.01 & -.03 & -.18 & -.08 & -.09 & .26 \\
\hline \multicolumn{7}{|l|}{ PTSD } \\
\hline Intrusive experiences & .18 & $.30 *$ & $.40 * *$ & $.32 *$ & .25 & -.07 \\
\hline Avoidance & .05 & .23 & $.32 *$ & .21 & $.26^{\dagger}$ & $-.34 *$ \\
\hline Hyperarousal & .23 & $.34 *$ & $.43 * *$ & $.37 *$ & $.25^{\dagger}$ & $-.32 *$ \\
\hline \multicolumn{7}{|l|}{ Other health indicators } \\
\hline Had dementia & .09 & .10 & .17 & .13 & .15 & $-.30^{\dagger}$ \\
\hline Physical health & .06 & .16 & -.02 & .08 & -.03 & .07 \\
\hline Physical mobility & -.03 & -.06 & -.05 & -.06 & -.23 & -.01 \\
\hline Socialize & $.37 *$ & $.26^{\dagger}$ & $.34 *$ & $.36 *$ & -.02 & -.07 \\
\hline
\end{tabular}

${ }^{\dagger} p<.10 * p<.05 * * p<.01$. Two-tailed.

Note. Ns range from 38 to 48 . 
Table 12

Correlations Between Participants' Demographic Characteristics and the

Conceptual Variables of the Study

\begin{tabular}{|c|c|c|c|c|c|c|}
\hline Conceptual variable & $\underline{\text { Gender }}^{\mathrm{a}}$ & $\underline{\text { Age }}$ & Education & $\begin{array}{c}\text { Years } \\
\text { experience }\end{array}$ & $\begin{array}{c}\begin{array}{c}\text { Worker } \\
b\end{array} \\
\text { status }\end{array}$ & $\underline{\text { Contact }}^{\mathrm{C}}$ \\
\hline \multicolumn{7}{|l|}{ Training: } \\
\hline Gerontology & -.01 & -.10 & .18 & .20 & -.02 & $.43 * * *$ \\
\hline Trauma & -.04 & $-.30 *$ & .16 & -.10 & .02 & $.35^{* *}$ \\
\hline Senior trauma & .10 & -.15 & .09 & .04 & .07 & $.32 *$ \\
\hline Total training & .04 & -.21 & .18 & .07 & .01 & $.44 * * *$ \\
\hline Familiarity & .13 & $-.23^{\dagger}$ & .17 & -.03 & -.15 & $.66^{* * *}$ \\
\hline Attitudes & .00 & .09 & .06 & -.15 & -.05 & -.10 \\
\hline \multicolumn{7}{|c|}{ Traumagenic dynamics } \\
\hline Powerlessness & -.01 & -.19 & $.24^{\dagger}$ & -.08 & -.02 & .20 \\
\hline Betrayal & .06 & -.18 & .20 & -.12 & -.10 & $.30^{*}$ \\
\hline Verbal abuse & -.15 & $-.23^{\dagger}$ & $.36 * *$ & -.19 & -.08 & .19 \\
\hline Physical abuse & -.11 & $-.28 *$ & .11 & -.11 & -.18 & .11 \\
\hline Touch sexually & .01 & $-.23^{\dagger}$ & .10 & -.00 & -.18 & .13 \\
\hline Neglect & -.15 & -.02 & $.31 *$ & .01 & -.02 & .02 \\
\hline
\end{tabular}

${ }^{\dagger} p<.10 * p<.05 * * p<.01 * * * p<.001$. Two-tailed.

Note. Ns range from 41 to 62 .

' Gender coded ' 0 ' for male and ' 1 ' for female.

b Worker status coded ' 1 ' for full-time, '2' for part-time, and ' 3 ' for casual.

${ }^{\mathrm{C}}$ Contact coded ' 0 ' for 'behind-the-scenes' support services and ' 1 ' for 'front-line' occupations. 
Table 12 Cont'd

Correlations Between Participants' Demographic Characteristics and Conceptual Variables of the Study

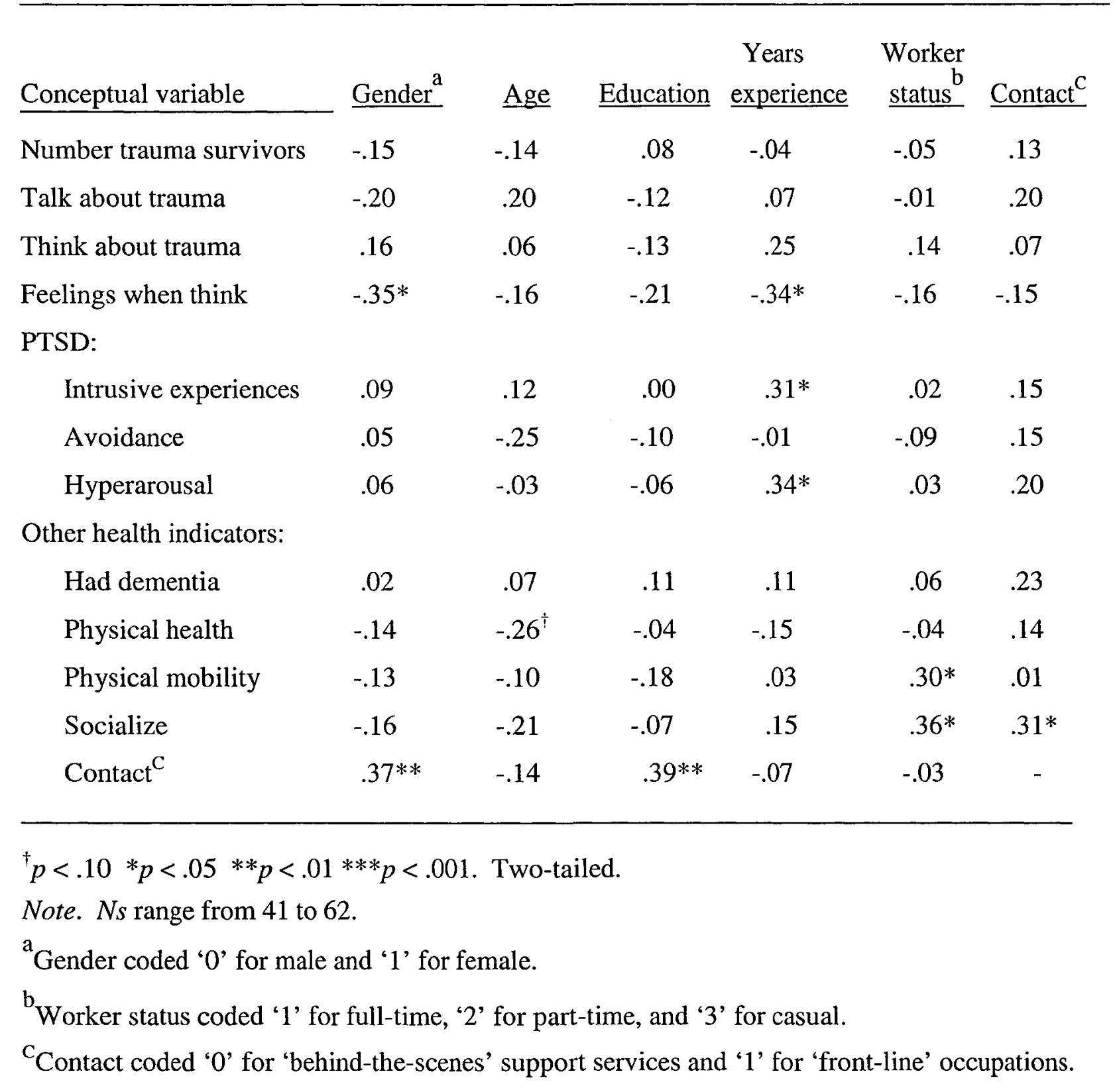


Table 13

Descriptive Statistics for Variables that Differed as a Function of Contact

\begin{tabular}{|c|c|c|c|c|}
\hline \multirow[b]{2}{*}{ Variable } & \multicolumn{2}{|c|}{ Behind-the-scenes $(n=13)$} & \multicolumn{2}{|c|}{ Front-line $(n=49)$} \\
\hline & $\underline{M}$ & $\underline{S D}$ & $\underline{M}$ & $\underline{S D}$ \\
\hline Training & 0.49 & 0.72 & 1.59 & 0.99 \\
\hline Gerontology & 0.67 & 1.15 & 2.14 & 1.26 \\
\hline Trauma & 0.54 & 0.97 & 1.51 & 1.12 \\
\hline Senior trauma & 0.31 & 0.63 & 1.10 & 1.03 \\
\hline Familiarity & -1.08 & 0.59 & 0.29 & 0.66 \\
\hline Review residents' histories & 0.77 & 0.83 & 2.80 & 0.96 \\
\hline Get to know residents & 1.58 & 0.76 & 2.34 & 0.67 \\
\hline Work with same residents & 1.15 & 0.80 & 3.04 & 1.08 \\
\hline \multicolumn{5}{|l|}{ Traumagenic dynamics } \\
\hline Betrayal & 1.00 & 0.76 & 1.60 & 0.78 \\
\hline \multicolumn{5}{|l|}{ Other health indicators } \\
\hline Socialize & 0.00 & 0.00 & 1.12 & 0.73 \\
\hline
\end{tabular}

Note. The measure of total Familiarity was based on $\mathrm{Z}$ scores. 
Table 14

Reasons for Suspecting a Senior Resident was Traumatized

Acting as if reexperiencing a trauma $(N=22,71.0 \%)$

Distress at exposure to cues that might resemble an aspect of a trauma $(n=19)$

"Women afraid of male staff giving personal care." "Fear of confinement

(POW)." "Shower reminds of concentration camp." "Reaction to media pictures."

Acting as if a trauma were recurring $(n=6)$

"Saying, "He's raping me" during personal care by a male Health Care Aide."

"Holding arms over head in a protective manner." "Striking at an unseen threat."

Avoidance of stimuli potentially associated with a trauma $(N=7,22.6 \%)$

Avoiding thoughts, feelings or conversations $(n=2)$

"Avoid talking about the past." "Evasive when asked certain questions."

Avoiding activities, places or people $(n=5)$

"Refusal of care from male." "Resistance to care."

\section{Symptoms of increased arousal $(N=5,16.1 \%)$}

Irritability or outbursts of anger $(n=3)$ :

"Angry outbursts." "Grumpy"

Difficulty falling or staying asleep $(n=1)$ :

"Trouble sleeping because of nightmares; yelling out."

Exaggerated startle response $(n=1)$ :

"Nervous, jumpy." 
Table 14 Cont'd

Reasons for Suspecting a Senior Resident was Traumatized

\section{Associated PTSD features/Disorder of Extreme Stress $(N=22,71.0 \%)$}

Negative affect $(n=11)$ :

"Depressed." "Sad." "Emotional."

Distrust and paranoia $(n=8)$ :

"Distrustful/suspicious/paranoid." "Don’t trust men."

Withdrawn $(n=6)$ :

"Isolated."

Negative self-appraisals $(n=3)$ :

"Feeling dirty." "Low self-esteem." "Self-blame/self-degrading."

Need for control/predictability $(n=3)$ :

"Need control and structure." "Moving too fast when dressing them." "Upset if meds late or something missing from room."

Unclassified $(N=9,29.0 \%)$

Obsessive behaviour. "Missing limbs/scars." "Clinging to baby doll."

"Worsening of pre-morbid personality disorders or exaggerated traits." 
Table 15

Other Effects of Trauma on Senior Residents

Associated PTSD features/Disorder of Extreme Stress $(N=27,87.1 \%)$

Negative affect $(n=15)$ :

"Depressed." "Fragile emotions (cry easily)."

Distrust $(n=13)$ :

"Don't trust." "Constantly looking for abusers." "Paranoid/suspicious."

Withdrawn $(n=10)$ :

"Withdrawn (distant, don't socialize)." "Uncomfortable in groups."

Aggressive $(n=5)$ :

"Aggressive." "Physically aggressive with staff and other residents."

Negative self-appraisals $(n=1)$ :

"Feel inadequate/worthless."

Somatization $(n=1)$ :

"Preoccupied with physical problems."

Symptoms of increased arousal $(N=10,32.3 \%)$

Irritability or outbursts of anger $(n=6)$ :

"Irritable/short temper/no patience." "Combative (Yelling out)." Difficulty

falling or staying asleep $(n=2)$

Other signs $(n=3)$ :

"Agitation." "Pacing, agitation." "Restlessness."

Avoidance of stimuli potentially associated with a trauma $(N=6,19.4 \%)$

Efforts to avoid activities, places or people that arouse recollections of the trauma $(n=6)$ :

"Refusing care of a male Health Care Aide."

"Resistive to care." "Difficult to bathe."

Loss of interest in activities $(n=1)$ :

"More apathetic." 
Table 15 Cont'd

Other Effects of Trauma on Senior Residents

Acting as if reexperiencing a trauma $(N=2,6.5 \%)$

"Constantly reminded of past."

Problematic attachment $(N=4,12.9 \%)$

"Cling to one staff member looking for reassurance and upset if off-duty."

Other/Unclassified $(N=9,29.0 \%)$

"Falsification of stories to replace bad ones."

"Bizarre conversation."

"Obsessive-compulsive behaviours (check bank balances, hoarding, layering clothes)."

"Difficulty adjusting to communal living." 
Table 16

Factors that Make Trauma Survivors Think of Their Trauma

Invasive procedures $(N=25 ; 65.8 \%)$

Personal care $(n=22)$ :

"Personal care (especially genitalia)." "Male bathing female."

Medical procedures $(n=3)$ :

"Medications and injections."

Media $(N=14,36.8 \%)$ :

"News events that parallel the past." "Media (catastrophic events in the news)."

People $(N=14 ; 36.8 \%)$

"Male staff." "People in uniforms." "Having a room mate." "Visits from family

(confusion; mix up son for abusive husband)." "Small children visiting (worried about their safety)." "Medical staff."

Physical environment $(N=12 ; 31.6 \%)$

"Time of day (night = dark)." "Lights off." "Locked unit." "Loud noises (fire alarms, construction)." "Fire alarms remind of sirens in war."

Psychological factors $(N=6 ; 15.8 \%)$

"Nightmares; recurrent dreams." "Reminiscing." "Loneliness." "Boredom."

"Feeling neglected because family not visiting."

Facility routines $(N=5 ; 13.2 \%)$

"Staff doing check at night with flashlights." "Being restrained." "Lining up in hallways."

Special events $(N=5,13.2 \%)$

"Remembrance Day for vets." "Jewish holidays."

Old songs $(N=4 ; 10.5 \%)$

Conversations $(N=4 ; 10.5 \%)$

"What is said." "Tone of voice."

Other/Unclassified $(N=8 ; 21.1 \%)$

"Pain." "Fighting." "Some activities." "German language." 
Table 17

Factors Facilitating Senior Trauma Survivors' Well-Being

External resources $(N=22,50.0 \%)$

Psychogeriatric support $(n=8)$ :

"Outside support for clients." "Psychogeriatric support." "Counseling (personal/external counseling)." "Assess for depression."

Training and education $(n=22)$ :

"Educate and mentor staff." "Teach ways to meet their needs." "Knowledge of proper care/procedures."

Internal resources $(N=19,43.2 \%)$

Adequate staffing $(n=19)$ :

"Shortage of staff." "Better staff/resident ratios." "More time is needed to accommodate them." "Too many that need attention." "Unavailability of female health care aides." "Only females could work with her."

Medical resources $(n=4)$ :

"Medication to calm." "Medicate and medical review."

Interpersonal resources $(N=14,31.8 \%)$

Good relations with family members $(n=8)$ :

"Involve family." "Family support." "Ask family to attend during a task."

Good inter-staff relations $(n=8)$ :

"Small group discussions to address staff concerns." "Talk to other staff

regarding techniques." "More praise when things are handled well." 
Table 17 Cont'd

Factors Facilitating Senior Trauma Survivors' Well-Being

Positive procedures or approaches $(N=41,93.2 \%)$

Communicate $(n=33)$ :

"They have much to teach us if we respond to non-verbal clues." "Listen."

"Talk, communicate, allow resident to lead session." "Explain all tasks

beforehand." "Treat with respect by calling them Mr. and Mrs." "Do not talk

about them to work partner as if they're not there." "Ask permission before

providing care." "Let them know when behaviour is disruptive."

Reassure the resident $(n=25)$ :

"Spoke calmly." "Gentle soft voice." "Compassion." "Patience." “Assuring they are safe and all is ok." "Give constant attention during episode." "Allow resident to stay close (e.g., sit near med cart so they can see you)." "Encourage to touch things (lights to see how they work)."

Prevent triggers $(n=25)$ :

"Noise." "Do everything slowly at the resident's pace." "Crowds." "If a certain staff is triggering behaviour, switch staff." "Avoid reminders of trauma (Remembrance Day services)." "Special care when bathing if sexually abused (covered with towels to prevent anyone from seeing naked)." "Avoid war news." "Be aware of need for physical/personal space." "[Avoid] Topics of conversation (war, death, murder)." 
Table 17 Cont'd

Factors Facilitating Senior Trauma Survivors' Well-Being

Know trauma history $(N=15,34.1 \%)$

"Know trauma and family history." "Know individual triggers." "At intake, have family fill in a form asking about trauma history." "Assess trauma at intake: at this age seniors do not disclose."

Individualized care $(N=10,22.7 \%)$

"Individual strategies for resident/family." "Meet special needs as much as possible." Every situation is unique and needs to be accommodated." Give choice (sense of autonomy)."

Redirect the resident $(N=7,15.9 \%)$

"Distractions (food, talking)." "Redirect to comfort and put radio on." "Divert minds with social activities." "More activities to engage their minds."

Team approach $(N=7,15.9 \%)$

"Team discussions, sharing, care mapping." "Careful note-taking to pass on information to other staff." Behavioural care plans." Develop care plan to meet needs." 
Table 18

Factors Detracting From Senior Trauma Survivors' Well-Being

Negative procedures and approach $(N=31,64.6 \%)$

Using force $(n=14)$ :

"Force care." "Insist they take a bath/shower."

"Careful not to discuss past with them unless they bring it up."

Acting unpredictably $(n=13)$ :

"Rushing care." "Never sneak up from behind."

"Prepare food and meds in front of them."

Abusing the resident psychologically, verbally or physically $(n=13)$ :

"Threatening approach." "Never judge." "Laughing, mocking, teasing."

"Talk down to them." "Get angry (yell, take it personally)." "Hit back."

Exposing to triggers $(n=6)$ :

"Cannot do night rounds as it terrifies patients." "Put in large groups."

Brushing off their experiences $(n=4)$ :

"Denying what the resident was feeling was real."

"Do not brush off as dementia, may be reliving trauma." 
Table 19

Caregivers' Personal Burden

\section{Causes:}

Uncertainty $(n=10)$ :

"Sometimes unsure of situation." "Difficult to gauge mood."

"Triggers unknown/subliminal."

Uneducated coworkers $(n=4)$ :

“Try to explain to workers, but it's like banging your head against a brick wall."

"Dealing with uneducated staff."

Being abused $(n=3)$ :

"Being yelled at is stressful every shift." "Hard when they are yelling and calling you names." "Do not abuse resident (hit, slap, kick, swear) even when they're doing it to you."

\section{Consequences:}

Guilt and self-blame $(n=6)$ :

"Do not take it personally." "Knowing relivings are a result of my intervention." "Hard to watch them relive trauma (usually need to be sedated)."

Physiological stress $(n=1)$ :

"Trouble sleeping." 
Appendix B

Research Materials 


\section{Statement of Consent:}

\section{Working with Senior Trauma Survivors in Residential Care Survey}

I hereby give permission to Connie M. Kristiansen, Ph.D., and Darcy Ammerman, MA candidate, of the Department of Psychology at Carleton University to distribute the "Working with Senior Trauma Survivors in Residential Care Survey." I realize that the survey contains questions asking staff members about their background and training, their experiences working with senior residents, and their experiences working with senior residents who experienced trauma earlier in their lives. I also realize that staff members' responses will be entirely confidential. I am aware that my consent to have the study conducted at this facility is voluntary, that I can have the study stopped at any time for any reason, and that the name of this facility will not be revealed in any discussion or publication of the findings outside this facility.

I have also been informed that:

- $\$ 150$ will be given to the facility as a way of thanking the staff for their time and effort. It is agreed that this money will be used to replace staff members who take time away from work for staff training and development.

- A written summary of the findings for this facility will be provided to me and the staff.

- The researchers will provide our facility with a training workshop during which we will be told about the findings of the study and given information about ways of working with senior trauma survivors.

Name:

Position:

Facility:

Signature:

Witness name:

Witness signature:

Date: 
Facility Information for:

$$
\text { (name of facility) }
$$

1. At your facility, about how many people are employed in the following positions:

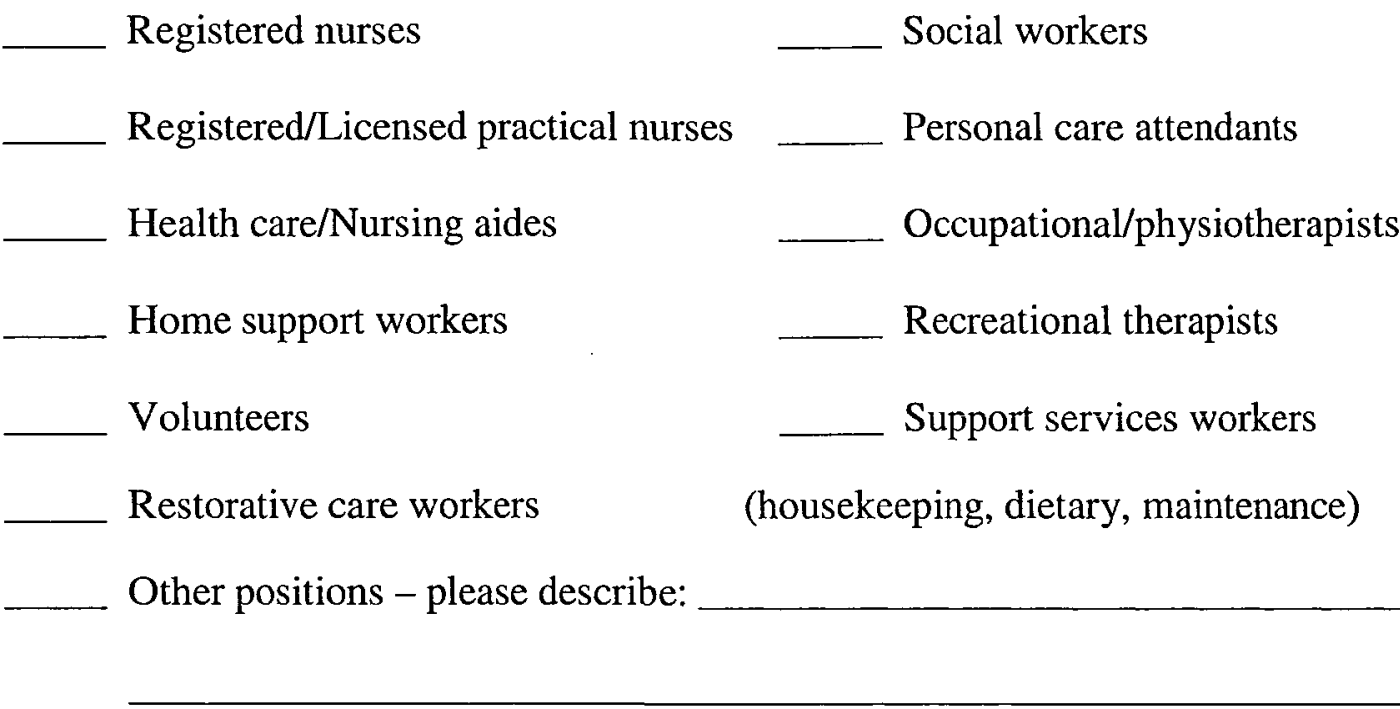

2. What percentage of your facility employees are:

— $\%$ Part-time workers $\%$ Full-time workers $\%$ Casual workers

3. How many residents live in your facility? residents

4. What percentage of these residents are female? $\%$ female

5. How would you describe your residents' ethnic/cultural backgrounds?

6. On admission, do you explicitly make inquiries into a resident's history of interpersonal trauma (i.e., child abuse, rape or partner abuse, being a war veteran or concentration camp/Holocaust survivor)?

_ No, never __ Yes, sometimes __ Yes, most times _ _ Yes, always 
7. Do you have any treatment resources for senior residents with psychological problems?

No

Yes - Please describe:

8. Does your facility have any treatment resources specifically for senior residents who experienced interpersonal trauma earlier in life (e.g., war, concentration camps, the Holocaust, child abuse, partner abuse, etc.)?

No

Yes - Please describe:

9. Does your facility provide any staff training regarding the effects of earlier life trauma (e.g., war, concentration camps, child abuse, partner abuse, etc.) on residents?

No

Yes - Please describe: 


\section{On Carleton University Letterhead}

\section{Working with Senior Trauma Survivors in Residential Care Survey}

Your Director of Care/Administrator, insert name, has given us permission to distribute this survey of staff's experiences working with seniors who experienced interpersonal trauma earlier in the lives, as children or adults. By "interpersonal trauma" we mean extremely distressing events that make a person feel overwhelmed, helpless and frightened, like being involved in combat during a war, being held in a concentration camp during the Holocaust, being physically or sexually abused as a child, being beaten by a partner, or being raped. The goal of this research is to identify the issues residential workers experience when working with senior trauma survivors and ways of helping both senior trauma survivors and those who work with them. The study is being conducted by Connie M. Kristiansen, Ph.D., and Darcy Ammerman, MA Candidate, of the Department of Psychology at Carleton University in Ottawa and is being funded by the Social Sciences and Humanities Research Council of Canada.

In this survey, you will be asked about your background and training. So we can learn what being in residential care might be like for seniors in general, questions will also ask about your experiences working with senior residents in general (i.e., residents aged 65 and older). Then, so we can learn about the issues workers experience when working with senior trauma survivors and how they deal with these issues, questions will ask about your experiences working with senior residents who were traumatized earlier in life (e.g., child abuse survivors, Holocaust survivors, war vets, and survivors of partner abuse or rape).

We have tried to make the questionnaire as short as possible and would be very grateful if you could take about 30 minutes to complete the survey. As a way of thanking the staff for their effort and time, we will give $\$ 800$ to your facility. This money will be used to replace staff members who take time away from work for staff training and development. We will also provide your facility with a training workshop during which we will tell you about the findings of the study and teach you about working with senior trauma

Please turn over to back of page $\Rightarrow$ 
survivors. Finally, we will post a copy of the findings in name of common staff area of your facility.

For some people, answering questions about their experiences working with senior trauma survivors may be upsetting because it reminds them of their own experiences of trauma. It is therefore important that you understand that your participation is entirely voluntary, and that you are free to refuse to answer any question. If you are in any way upset by participating in this study and feel the need to talk to someone, you can call the 24-hour Ottawa Region Distress Centre at (613) 238-3311. You can also call Dr. Jan Heney at (613) 244-9934, a registered clinical psychologist who has agreed to provide consultation to anyone who is distressed by their participation in this survey, at no cost to them.

When you have finished the survey, you can return it to the insert name of place where box is located, where there is a locked box labeled "Working with Trauma Survivors Survey." Because the box is locked, only we, the researchers will have access to your survey responses. In addition, your answers will be entirely confidential and will not be disclosed to anyone outside the research team. If you have any questions about completing the survey or the study more generally you are welcome to contact Connie Kristiansen at (613) 520-2600 ext. 2674 (e-mail: ckristia@ccs.carleton.ca) or Darcy Ammerman at (613) 520-2600 ext. 2679 (e-mail: bluestsolar@hotmail.com). If you have any concerns about any ethical aspects of the study, you are invited to contact Dr. Chris Davis, Chair of the Carleton University Research Ethics Committee for Psychological Research, at (613) 520-2600 ext. 2251. If you have any concerns about any other aspects of the study please contact Dr. Mary Gick, Chair of the Department of Psychology at (613) 520-2600 ext. 2664. Finally, your completion and return of the survey will be taken as your consent to participate in this study.

Thank you for your consideration, time and effort,

Connie M. Kristiansen, Ph.D. Associate Professor of Psychology

P.S. Please keep this page for future reference.
Darcy Ammerman

M.A. Candidate 